OPEN ACCESS

Edited by:

Rustam Aminov,

University of Aberdeen,

United Kingdom

Reviewed by:

Hongshun Yang,

National University of Singapore,

Singapore

Lionel Tarrago,

Institut National de Recherche pour

l'Agriculture, l'Alimentation et

l'Environnement (INRAE), France

${ }^{*}$ Correspondence:

Simon V. Avery

Simon.Avery@nottingham.ac.uk

Specialty section:

This article was submitted to Antimicrobials, Resistance

and Chemotherapy,

a section of the journal

Frontiers in Microbiology

Received: 22 June 2020 Accepted: 07 September 2020 Published: 25 September 2020

Citation:

Wohlgemuth F, Gomes RL, Singleton I, Rawson FJ and Avery SV

(2020) Top-Down Characterization of an Antimicrobial Sanitizer, Leading From Quenchers of Efficacy to Mode

of Action.

Front. Microbiol. 11:575157. doi: 10.3389/fmicb.2020.575157

\section{Top-Down Characterization of an Antimicrobial Sanitizer, Leading From Quenchers of Efficacy to Mode of Action}

\author{
Franziska Wohlgemuth ${ }^{1}$, Rachel L. Gomes ${ }^{2}$, lan Singleton ${ }^{3}$, Frankie J. Rawson ${ }^{4}$ and \\ Simon V. Avery ${ }^{\text {* }}$ \\ 'School of Life Sciences, University of Nottingham, Nottingham, United Kingdom, ${ }^{2}$ Faculty of Engineering, University \\ of Nottingham, Nottingham, United Kingdom, ${ }^{3}$ School of Applied Sciences, Edinburgh Napier University, Edinburgh, \\ United Kingdom, ${ }^{4}$ School of Pharmacy, University of Nottingham, Nottingham, United Kingdom
}

We developed a top-down strategy to characterize an antimicrobial, oxidizing sanitizer, which has diverse proposed applications including surface-sanitization of fresh foods, and with benefits for water resilience. The strategy involved finding quenchers of antimicrobial activity then antimicrobial mode of action, by identifying key chemical reaction partners starting from complex matrices, narrowing down reactivity to specific organic molecules within cells. The sanitizer electrolyzed-water (EW) retained partial fungicidal activity against the food-spoilage fungus Aspergillus niger at high levels of added soils (30-750 $\mathrm{mg} \mathrm{mL}^{-1}$ ), commonly associated with harvested produce. Soil with high organic load $\left(98 \mathrm{mg} \mathrm{g}^{-1}\right.$ ) gave stronger EW inactivation. Marked inactivation by a complex organics mix (YEPD medium) was linked to its protein-rich components. Addition of pure proteins or amino acids $\left(\leq 1 \mathrm{mg} \mathrm{mL}^{-1}\right)$ fully suppressed EW activity. Mechanism was interrogated further with the yeast model, corroborating marked suppression of EW action by the amino acid methionine. Pre-culture with methionine increased resistance to EW, sodium hypochlorite, or chlorine-free ozonated water. Overexpression of methionine sulfoxide reductases (which reduce oxidized methionine) protected against EW. Fluoroprobe-based analyses indicated that methionine and cysteine inactivate free chlorine species in EW. Intracellular methionine oxidation can disturb cellular FeS-clusters and we showed that EW treatment impairs FeS-enzyme activity. The study establishes the value of a top-down approach for multi-level characterization of sanitizer efficacy and action. The results reveal proteins and amino acids as key quenchers of EW activity and, among the amino acids, the importance of methionine oxidation and FeS-cluster damage for antimicrobial mode-of-action.

Keywords: antimicrobial sanitizer, mode of action, oxidative stress, methionine, fungi, yeast, soil organics, electrolyzed water

\section{INTRODUCTION}

Chemical sanitizers and disinfectants have applications for control of microbial contamination and growth in diverse settings, including healthcare and food industries as well as domestic use, with a global market approaching USD 20 billion. That looks set to increase markedly with the heightened public awareness and concern arising from the COVID-19 pandemic. For applications 
of antimicrobial sanitizers to be effective, there is a need to understand limiting factors associated with chemical matrices presented by the relevant applications, ideally supported by understanding of antimicrobial mode-of-action. Here, we present a top-down approach which allows both these critical aspects to be addressed, where chemical understanding then informs modeof-action characterization. We use the sanitizer electrolyzed water (EW) as an exemplar. Electrolyzed water has been used for water decontamination and surface disinfection of medical equipment for several decades (Hricova et al., 2008). More recent applications have been reported in the food industry, including processing-water sanitization and surface sanitization of factory surfaces and equipment, and of fresh produce (Gil et al., 2015; Kaczmarek et al., 2019). It has been estimated that at least $14 \%$ of global food production is lost at the post-harvest level up to (not including) the retail level, with roots, tubers, oil-bearing crops, fruits and vegetables contributing the most to food losses (FAO, 2019). One major contributor to this loss is microbial spoilage, including by molds such as Aspergillus niger, a common food spoilage mold found on diverse fruits and vegetables (Taniwaki et al., 2018). A range of preservation methods are used to help mitigate losses to such mold spoilage, but the problem persists. Electrolyzed water can be very effective in killing a range of foodrelevant bacteria and fungi (Hricova et al., 2008; Huang et al., 2008). The guidelines for sanitizers to achieve $>5 \log$ reduction (Block, 2001) are usually met with EW for microorganisms in suspension, but lower efficiencies have been reported for certain species or conditions.

Electrolyzed water can be generated using only clean water and salt $(\mathrm{NaCl})$ as substrates, either in two-cell electrochemical systems (to generate acidic and basic EW versions) or in single cell units as with the EW used in this study (Huang et al., 2008; Zhang et al., 2018). Main advantages of EW compared to other sanitizers are that EW allows on-site production from cheap, safe substrates, eliminating the need for transport, handling and storage of concentrated chemical disinfectant, and that it can be inactivated after use simply by mixing with organic matter (Gil et al., 2015). Reducing the usage and chemical contamination of clean water is desirable considering that $29 \%$ of the world's population lack access to safe drinking water and water resources are expected to be negatively impacted by diverse climate change related events (UNESCO, 2019).

Generation of EW involves the formation of free chlorine species $\left(\mathrm{Cl}_{2}, \mathrm{HOCl},-\mathrm{OCl}\right)$, and other active compounds at low levels, including ozone $\left(\mathrm{O}_{3}\right)$, chlorine dioxide $\left(\mathrm{ClO}_{2}\right)$, hydrogen peroxide, superoxide and hydroxyl radicals (Jeong et al., 2009; Zhang et al., 2018). Many of the non-chlorine components are unstable. Among the chlorine species found in EW, hypochlorous acid ( $\mathrm{HOCl})$ has the strongest antimicrobial effect but dissociates to hypochlorite $\left({ }^{-} \mathrm{OCl}\right.$ ) between $\mathrm{pH} 6.5$ and 8.5 and forms $\mathrm{Cl}_{2}$ gas at very low $\mathrm{pH}(<3)$ (Rahman et al., 2016). The sum of these species is referred to as free available chlorine (FAC, sometimes FC or ACC) (Gil et al., 2015). The FAC in EW can react with inorganic and organic compounds such as ammonia and amino acids (Oomori et al., 2000). Therefore, when applying EW in food production, the organic compounds from food products or in the water or soil could, depending on their concentrations and chemistry, react with the FAC and affect antimicrobial activity. The effect will also depend on the reactivity of such compounds with the different EW components (including non-chlorine species) whose relative contributions to overall EW action are unclear. Compared to conventional sanitation with dissolved hypochlorite salts such as $\mathrm{NaOCl}$, the additional non-chlorine active species can increase the efficacy of EW (Graça et al., 2020). The sanitizer ozonated water is a chlorine-free alternative that is also produced by electrolysis and contains ozone and other reactive oxygen species, but has a lower stability compared to FAC based sanitizers (Baggio et al., 2020; Wang et al., 2020).

Treatment of fungi with FAC or other reactive oxygen species (ROS) promotes oxidative stress and oxidative damage to cellular macromolecules (Avery, 2011; Carmona-Gutierrez et al., 2013). One key molecular target of oxidative stress is iron-sulfur (FeS) cluster proteins (Imlay et al., 2019). FeS-cofactors are found in proteins required for diverse cellular functions, including translation, protein regulation, citric acid cycle, mitochondrial electron transport chain and DNA binding (Cardenas-Rodriguez et al., 2018). Cellular defense from oxidative stress arises through ROS scavenging molecules (antioxidants) and enzymatic systems (Wang et al., 2019). Among the latter, methionine sulfoxide reductases (MSRs) have been shown to help preserve the integrity of FeS-clusters during oxidative stress (Sideri et al., 2009; Alhebshi et al., 2012). The MSR enzymes reduce oxidized methionine (methionine sulfoxide, MetO), effectively functioning as a ROS scavenging system (Brot et al., 1981; Grimaud et al., 2001). The MSRs are highly conserved across evolution (Delaye et al., 2007). In the yeast model of eukaryotes, three different MSRs (MsrA, MsrB, and fRMsr) reduce different MetO isomers including protein-bound MetO (Le et al., 2009). This allows methionine to act as an antioxidant in proteins (protecting other residues from oxidation) and as a regulator of protein activity (Kim et al., 2014).

Here, we investigate the fungicidal activity of EW against the major food spoilage fungus $A$. niger. Results were informed further by mechanistic analyses carried out in the yeast model Saccharomyces cerevisiae, also a food spoilage fungus, capitalizing on the extensive understanding and experimental tools available with this organism. The study highlights diverse impacts on EW efficacy of different, incidental organic-material sources. By progressively narrowing down the species of organic material that impact EW activity, we were able to develop and test hypotheses, so revealing new insight to the mechanism of EW action in cells. The outcomes highlight the value of this top-down approach for gaining a comprehensive understanding of how antimicrobial actives may work.

\section{MATERIALS AND METHODS}

\section{Fungal Strains and Growth Conditions}

The study used the filamentous fungus Aspergillus niger N402 (ATCC 64974), and yeast strains Saccharomyces cerevisiae BY4741 (MATa; his3-1; leu2-0; met15-0; ura3-0), BY4742 (MAT $\alpha$, his3-1; leu2-0; ura3-0; lys2-0) and deletion mutants isogenic with the BY4741 parent: $\operatorname{trp} 1 \Delta$, alt1 $\Delta$, $\arg 4 \Delta$ (from Euroscarf, 
Germany). The MSRA and MSRB genes were overexpressed in multicopy plasmids YEp351 and YEp352, respectively, as described previously (Sumner et al., 2005). Overexpression of FeS proteins was with the previously constructed plasmids pCM190-RLI1-HA (Alhebshi et al., 2012) and pCM190-YAH1HA (Vallières et al., 2017). Aspergillus niger was maintained and grown at $28^{\circ} \mathrm{C}$ on Potato Dextrose Agar (PDA, Oxoid) or YEPD $(2 \%[\mathrm{w} / \mathrm{v}]$ bacteriological peptone (Oxoid, Basingstoke, United Kingdom), 1\% [w/v] yeast extract (Oxoid), 2\% [w/v] Dglucose). Conidia were harvested in $0.1 \%$ [v/v] Tween 80 from PDA slopes after 1 week of growth, filtered through a $40 \mu \mathrm{m}$ cell strainer and spore densities were counted in a hemocytometer. Yeast strains were cultured at $30^{\circ} \mathrm{C}$ in either YEPD broth or, where indicated, YNB broth $(0.69 \%$ yeast-nitrogen base without amino acids (Formedium, Norfolk, United Kingdom), 2\% [w/v] D-glucose). Amino acids or uracil were added to YNB as needed for strain auxotrophies or plasmid selection. Where necessary, media were solidified with $2 \%[\mathrm{w} / \mathrm{v}]$ agar (Sigma-Aldrich, St. Louis, MO, United States).

\section{Electrolyzed Water (EW), $\mathrm{NaOCl}$ and Ozonated Water}

Eloclear $^{\circledR}$ electrolyzed water (EW) was provided by Ozo Innovations (Kidlington, United Kingdom). The EW was manufactured electrochemically in single-cell units with a $\mathrm{pH}$ $\sim 8.7-9.3$ and a free available chlorine (FAC) concentration between 1800 and $2000 \mathrm{mg} \mathrm{L}^{-1}$, determined (and checked prior to experiments) using the $\mathrm{HACH}^{\circledR}$ DPD Free Chlorine Reagent (Permachem ${ }^{\circledR}$ ) in a $\mathrm{HACH}^{\circledR}$ Pocket Colorimeter $^{\mathrm{TM}}$ II. EW was stored in plastic containers in the dark at $4^{\circ} \mathrm{C}$ for up to 2 weeks. Dilutions (v/v) were prepared in HPLC grade water immediately prior to use. $\mathrm{NaOCl}$ solution was purchased from ACROS Organics $^{\mathrm{TM}}$, Fisher Scientific (5\% chlorine). Ozonated water was produced using an Enozo Sanitizing Spray Bottle (SB-100HD) from Enozo Technologies, Inc. (North Andover, MA, United States), kindly provided by GreenTeck Global (Wallingford, United Kingdom). The bottle was filled with sterile filtered tap water $\left(4^{\circ} \mathrm{C}\right)$ and ozonated water was produced by spraying for $5 \mathrm{~s}$. The water was used within $30 \mathrm{~s}$ (in vitro experiments) or $2 \mathrm{~min}$ (yeast treatments) of its generation.

\section{Soil Samples}

Soil samples from arable land with varying chemical and textural properties were kindly provided by Hannah Cooper (University of Nottingham). The soil properties are listed in Supplementary Table S1. An additional uncharacterized sample ("soil 8") was autoclaved soil from an untreated control site at the Woburn long-term sludge experiment, United Kingdom ${ }^{1}$. All samples were sterilized using $\gamma$-irradiation for 4 days, corresponding to a total dose of $22-26 \mathrm{kGy}$. Samples were then dried at $37^{\circ} \mathrm{C}$ for 4 weeks until a constant weight was reached.

\section{EW Treatment of $A$. niger}

Electrolyzed water was diluted in sterile water to $400-450 \mathrm{mg} \mathrm{L}^{-1}$ FAC and either mixed or not with different organics (soil samples,

${ }^{1}$ http://www.era.rothamsted.ac.uk/Other\#SEC11
YEPD components, proteins, amino acids). Organics solutions were substituted with sterile water in controls. Five minutes after mixing with $\mathrm{EW}$, the solutions were used to treat conidia $\left(10^{5}\right.$ spores $\left.\mathrm{mL}^{-1}\right)$ at final concentrations of $360-400 \mathrm{mg} \mathrm{L}^{-1} \mathrm{FAC}$, $\leq 0.01 \%$ Tween 80 . After defined treatment periods (1-7 $\mathrm{min})$, EW treatments were stopped by mixing with an equal volume of two-times concentrated (2X) YEPD. Appropriate dilutions were plated onto YEPD agar and incubated for at least 2 days, $28^{\circ} \mathrm{C}$ before colony enumeration. For recovery in broth after EW treatment, $100 \mu \mathrm{L}$ samples were transferred to 96 well plates and incubated statically at $30^{\circ} \mathrm{C}$. Growth was determined by $\mathrm{OD}_{600}$ readings at appropriate time points in a BioTek ${ }^{\circledR}$ EL800 microplate reader.

\section{EW Treatment of S. cerevisiae}

Experimental yeast cultures were inoculated to $\mathrm{OD}_{600} \sim 0.5$ from overnight starter cultures in broth (from single colonies) and cultured to exponential phase $\left(\mathrm{OD}_{600} \sim 1.8\right)$ in $\mathrm{YNB}$ broth. For amino acid pre-culture experiments, different amino acids, S-adenosyl methionine chloride dihydrochloride (SAM, $\geq 75 \%$ purity) or $\mathrm{N}$-acetyl cysteine (NAC) at up to $0.3 \mathrm{mM}$ were included in the experimental cultures. All pre-culture conditions were in buffered YNB (0.1 M potassium phosphate $\mathrm{pH}$ 6.0), apart from experiments that included Met pre-culture only. Cells were harvested by centrifugation, washed two times in equal volumes of HPLC grade water, and diluted to $\mathrm{OD}_{600} \sim 2$ in HPLC grade water. Aliquots of $10 \mu \mathrm{L}$ cell suspension were transferred to 96 well plates, and treated for 5 min with $90 \mu \mathrm{L}$ of either diluted EW (0.5-1 $\mathrm{mg} \mathrm{L}^{-1}$ FAC), $\mathrm{NaOCl}\left(0.6-0.7 \mathrm{mg} \mathrm{L}^{-1} \mathrm{FAC}\right)$ or ozonated water. Treatments were stopped by adding $100 \mu \mathrm{L}$ of $2 \mathrm{X}$ YEPD. Aliquots $(100 \mu \mathrm{L})$ were transferred to fresh 96 well plates and cultured at $30^{\circ} \mathrm{C}$ with continuous linear shaking (1096 cycles $\min ^{-1}$ ) in 96 well plates in a BioTek microplate reader (Epoch2 or Synergy HTX). The $\mathrm{OD}_{600}$ was measured every $30 \mathrm{~min}$ and used to estimate survival as described below.

\section{Estimation of Yeast Survival According to Growth Recovery in Broth}

Growth curves from broth cultures after treatments (described above) were analyzed for the period of exponential growth using RStudio. For every six consecutive $\mathrm{OD}_{600}$ values during this period (overlapping; i.e., every string of $3 \mathrm{~h}$ within the exponential growth period), the exponential regression was determined. The 3-hour period with the highest slope was selected and extrapolation to the y-intercept of the regression was used as an estimate for density of viable cells at $t=0 \mathrm{~h}$, similar to the methods described by Fernández-Niño et al. (2018) and Qiu et al. (2017). For validation of the method, S. cerevisiae BY4741 was diluted and aliquots spread plated to determine linearity of correlation between values for calculated starting cell density $\left(\mathrm{OD}_{600}\right)$, viability (colony forming units, cfu) and the $\mathrm{y}$-intercept of growth in broth (Supplementary Figures S1A,B). Linearity of the correlation was also examined for cfu (agar) and y-intercept (broth) determinations with EW treated yeast cells. Here, some deviation may be caused by a growth delay of stressed cells (Lu et al., 2009), resulting in lower survival estimates based 
on the y-intercept compared to cfu enumeration (Supplementary Figures S1C,D). Throughout, EW was diluted to give estimated survival between 5 and 50\%. The lower limit was to counter experimental variation observed at very low starting viable-cell densities. The upper limit (50\%) was to minimize the relative influence of potential growth-delay effects (as opposed to cell death events) on the measurements: survival rates calculated with the present method are estimates as they may encompass a contribution from any lag phase extension, and will therefore be referred to as recovery rates after treatments.

\section{Determination of Protein and Humic Acid Contents of Soil Samples}

A citrate extraction and a modified Lowry assay were performed as described by Redmile-Gordon et al. (2013). Briefly, $8 \mathrm{~mL}$ of $20 \mathrm{mM}$ citrate buffer ( $\mathrm{pH} \mathrm{7}$ ) was added to $1 \mathrm{~g}$ of dried soil in $15 \mathrm{~mL}$ centrifuge tubes and autoclaved for $30 \mathrm{~min}\left(117^{\circ} \mathrm{C}\right)$. After autoclaving, the tubes were cooled on ice and then centrifuged $\left(3500 \times g, 20 \mathrm{~min}, 4^{\circ} \mathrm{C}\right)$. The supernatant was stored at $4^{\circ} \mathrm{C}$ for the Lowry assay. In an alternative citrate + SDS extraction protocol (Chen et al., 2009), $10 \mathrm{~mL}$ of $250 \mathrm{mM}$ citrate buffer ( $\mathrm{pH} 8$ ) was added to $1 \mathrm{~g}$ dried soil in $50 \mathrm{~mL}$ centrifuge tubes and shaken for $4 \mathrm{~h}$ (stuart ${ }^{\circledR}$ see-saw rocker SSL4, 70 rev. $\mathrm{min}^{-1}$, with vortexing at 0,2 , and $4 \mathrm{~h})$. After centrifugation $(2876 \times g$, $15 \mathrm{~min}, 4^{\circ} \mathrm{C}$ ), the supernatant was collected as "citrate extract". $10 \mathrm{~mL}$ SDS buffer (1\% [w/v] SDS, $0.1 \mathrm{M}$ Tris-HCl (pH 6.8), $20 \mathrm{mM}$ DTT) was added to the pellet, shaken for $30 \mathrm{~min}$ (seesaw rocker, as above), and centrifuged to obtain the supernatant ("SDS extract"). Both extracts were combined for the Lowry assay. For the assay, $50 \mu \mathrm{L}$ extract samples (diluted between 1:5 and 1:12.5 depending on the assay signal of the extract) were transferred to 96 well plates and mixed with $50 \mu \mathrm{L}$ of PBS containing either BSA as protein standard or a humic acid standard (standard concentrations in PBS: BSA, 40-640 mg $\mathrm{mL}^{-1}$; humic acid, $160-640 \mathrm{mg} \mathrm{mL}^{-1}$ ). Assay reagents $\mathrm{A}$ and $\mathrm{B}$ were prepared as described previously (Redmile-Gordon et al., 2013). To each extract + standard combination, $100 \mu \mathrm{L}$ of $\mathrm{CuSO}_{4}$-containing reagent $\mathrm{A}$ (in plate $\mathrm{A}$, for protein and humic acid determination) or of $\mathrm{CuSO}_{4}$-free reagent $\mathrm{B}$ (in plate $\mathrm{B}$, for humic acid determination) was added. From this point, the standard Lowry protocol (see below) was followed, except that $100 \mu \mathrm{L} 1 \mathrm{x}$ Folin-Ciocalteu Phenol reagent (Thermo Fisher) was added. After subtraction of a blank (PBS + reagents), the absorbance corresponding to protein $\left(A b s_{\text {prot }}\right)$ and humic acid $\left(A b s_{\text {hum }}\right)$, respectively, were calculated from the absorbance readings for plates $\mathrm{A}$ and $\mathrm{B}\left(A b s_{A}\right.$ and $\left.A b s_{B}\right)$ (Redmile-Gordon et al., 2013):

$$
A b s_{\text {prot }}=1.25\left(A b s_{A}-A b s_{B}\right) A b s_{\text {hum }}=A b s_{B}-0.2 A b s_{\text {prot }}
$$

\section{Determination of Protein Content in YEPD}

The Pierce ${ }^{\mathrm{TM}}$ Modified Lowry Protein Assay (Thermo Fisher) was performed according to the manufacturer's Microplate Procedure. Samples $(20 \mu \mathrm{L}$ of either YEP, peptone or yeast extract, diluted to between 100 and $600 \mathrm{mg} \mathrm{L}^{-1}$ ) were mixed with
$20 \mu \mathrm{L}$ BSA standard (25-750 $\left.\mathrm{mg} \mathrm{L}^{-1}\right)$. Modified Lowry Reagent $(200 \mu \mathrm{L})$ was added, before incubation for $10 \mathrm{~min}$ in the dark and subsequent addition of $20 \mu \mathrm{L}$ 1x Folin-Ciocalteu Phenol Reagent. After $30 \mathrm{~min}$ incubation in the dark, absorbance at $750 \mathrm{~nm}$ was determined in a BioTek ${ }^{\circledR}$ microplate reader (Epoch2).

\section{In vitro Assays With the Fluorescent Dyes APF and HPF}

The fluorescent probes hydroxyphenyl fluorescein (HPF) and aminophenyl fluorescein (APF) (Setsukinai et al., 2003) were supplied by Sigma-Aldrich at $5 \mathrm{mM}$ in dimethylformamide (DMF). These were diluted in HPLC grade water to $50 \mu \mathrm{M}$. Dye (10 $\mu \mathrm{L}$ of the $50 \mu \mathrm{M}$ dilution) was mixed with $10 \mu \mathrm{L}$ water or diluted amino acids (final assay concentration after oxidant addition was $1.2-10 \mu \mathrm{M}$ ), and $80 \mu \mathrm{L}$ oxidant (diluted $\mathrm{EW}, \mathrm{NaOCl}$ or pure ozonated water) was added. Fluorescence was recorded immediately (within 2 min of oxidant addition) and at further time points up to $1 \mathrm{~h}$, with excitation at 485/20 $\mathrm{nm}$ and emission at 528/20 nm (BioTek ${ }^{\circledR}$ microplate reader Synergy HTX).

\section{Aconitase and Fumarase Assay in Cell Extracts}

The method was as described previously (Lalève et al., 2016). Briefly, S. cerevisiae was grown to exponential phase in $50 \mathrm{~mL}$ YEPD (250 mL shake flasks). Cells were washed, pooled and treated with EW (except for in vitro EW treatments, described below) as outlined above, except that cell suspensions were concentrated to $\mathrm{OD}_{600} \sim 200$ in water and $1 \mathrm{~mL}$ suspension was

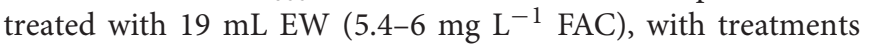
inactivated using $20 \mathrm{~mL}$ of $2 \mathrm{X}$ YEPD (for survival analysis, samples were taken at this point, diluted and spread to YEPD agar for cfu determination). Cells were harvested $\left(2876 \mathrm{~g}, 4^{\circ} \mathrm{C}\right.$, $10 \mathrm{~min}$ ), transferred to a $4^{\circ} \mathrm{C}$ room and resuspended in $250 \mu \mathrm{L}$ cold resuspension buffer $\left[0.72 \mathrm{mM} \mathrm{MnCl}_{2}\right.$ in $10 \mathrm{mM}$ MES (pH 6), Halt ${ }^{\mathrm{TM}}$ Protease Inhibitor Cocktail (1x), with oxygen depleted by pre-incubation in $10 \% \mathrm{CO}_{2}, 10 \% \mathrm{H}_{2}, 80 \% \mathrm{~N}_{2}$ for at least $2 \mathrm{~h}$ ]. Cells were lysed with $500 \mu \mathrm{L}$ cold glass beads [acid washed, 425-500 $\mu \mathrm{m}$ (Sigma Aldrich), pre-conditioned with resuspension buffer] and aliquots of the supernatants $(50 \mu \mathrm{L})$ frozen in liquid nitrogen and stored at $-80^{\circ} \mathrm{C}$. Protein concentrations in the extracts were determined with the Bio-Rad protein assay kit according to the manufacturer's Microassay Procedure. For in vitro EW treatments, $155 \mu \mathrm{g}$ protein extracted from untreated cells was mixed with EW (final concentration 180-200 $\mathrm{mg} \mathrm{L}^{-1}$ FAC) or primaquine $(500 \mu \mathrm{M})$ for $20 \mathrm{~min}$, in the absence or presence of $3 \mathrm{mM}$ methionine or cysteine. Aliquots comprising $140 \mu \mathrm{g}$ protein (from in vivo or in vitro treatments) were then mixed with aconitase buffer $(50 \mathrm{mM}$ potassium phosphate buffer [pH 7.4], $30 \mathrm{mM} \mathrm{DL-isocitric} \mathrm{acid} \mathrm{trisodium,} 0.6 \mathrm{mM} \mathrm{MnCl}_{2}$ ) or fumarase buffer $[50 \mathrm{mM}$ potassium phosphate buffer $(\mathrm{pH} 7.4)$, $50 \mathrm{mM}$ L-malic acid] to a total volume of $700 \mu \mathrm{L}$ in quartz cuvettes. The absorbance at $240 \mathrm{~nm}$ was recorded every $30 \mathrm{~s}$ for $30 \mathrm{~min}$ (baseline correction at $340 \mathrm{~nm}$ ). Enzyme activities were calculated from the resultant curves as described previously (Lalève et al., 2016). 


\section{Statistical Analysis}

Tests for statistical significance were according to a two-tailed paired $t$-test, correcting for multiple comparison by controlling the false discovery rate at FDR $<5 \%$, using a two-stage step-up method (Benjamini et al., 2006). The calculations were performed within GraphPad Prism 8 software. Paired tests were used to control for observed between-experiment variation in EW effectsize. At least three independent replicates were analyzed in each case. Significance was defined by a $p$-value $<0.05$. Linear regressions were calculated in Prism 8 , to determine $R^{2}$ and $p$ values.

\section{RESULTS}

\section{Electrolyzed Water Activity Tolerates High Levels of Added Soil}

Sanitizers ideally should have antimicrobial actions resilient to the presence of incidental substances or contaminants. Potential applications of EW in the fresh food industry, among other applications, may be affected by soil residues on produce or other contaminants; a factor that could alter EW activity. Effects of soil on EW activity were therefore tested. In standard experimental conditions, EW at a $20 \%$ [v/v] dilution (360$400 \mathrm{mg} \mathrm{L}^{-1} \mathrm{FAC}$ ) was sufficient to kill $>3 \mathrm{log}$ spores of the spoilage mold A. niger in $5 \mathrm{~min}$ (see "control" in Figure 1A; no colony formation detected when plating $\sim 2000$ spores per plate after EW treatment). Lower EW concentrations allowed greater spore survival (Supplementary Figure S2A). Adding soil to EW treatments (360-400 $\mathrm{mg} \mathrm{L}^{-1}$ FAC) inactivated EWdependent killing only at high soil levels (Figure 1A); the soil concentration $\left(750 \mathrm{mg} \mathrm{mL}^{-1}\right.$ ) shown in the figure was chosen after preliminary tests with soil " 8 " showed that lower soil additions were insufficient for suppressing EW activity. The data are also presented as survival rates in Figure 1B (linear scale) as this helps visualize differences in the sizes of the inactivation effects between the soil types. Four out of eight tested soils did not give full EW inactivation even at $750 \mathrm{mg} \mathrm{mL}^{-1}$. The strongest inactivation effect was observed for one soil sample (soil 4) which gave full inactivation of EW at $100 \mathrm{mg} \mathrm{mL} \mathrm{m}^{-1}$ and more limited EW action ( $<2$ log killing) at $30 \mathrm{mg} \mathrm{mL}^{-1}$ (Figures 1C,D). The soil concentrations necessary to inactivate EW were compared to a complex organics mix (YEPD, a fungal growth medium). This mix at only $5 \mathrm{mg} \mathrm{mL}^{-1}$ was sufficient to inactivate EW fully.

To explain the differences observed for the different soil types, and because YEPD contains high protein levels, the organic content of the soil samples was dissected. The protein content and the humic substance content of the soils were determined in citrate extracts and, to increase the range of extracted proteins, also in citrate + SDS extracts (Chen et al., 2009). Protein levels were very low (below $5-10 \mathrm{mg} \mathrm{g}^{-1}$ soil) compared to the humic substance levels and these low protein levels did not correlate with observed EW inactivation efficiency (Supplementary Figure S3). Soil 4 showed a high level of humic substances (in both types of extract) and had the strongest inactivating effect on EW (Figures 1C-E). Humic substances in soil extracts are formed by accumulation, aggregation and degradation of organic molecules during the extraction process (Lehmann and Kleber, 2015). The extraction methods used here do not claim full representation of all soil organics, but the comparison between the soil types indicates a higher organic content in soil 4 compared to the other soil types (see section "Discussion").

\section{EW Can Be Inactivated by Proteins and Amino Acids}

Because of the above indication of a relationship between soil organic load and EW inactivation, the complex organics mix of YEPD was selected for investigating the effects of different organic constituents of the medium. Increasing additions of YEPD progressively inactivated the fungicidal activity of EW (Figure 2A). YEPD consists of peptone $[40 \%(w / w)$ of the YEPD dry weight), yeast extract [YE, 20\% (w/w)] and glucose $[40 \%(w / w)]$. Two of the individual components (peptone and $\mathrm{YE}$ ) each had inactivating effects on EW, but glucose did not (Figure 2B). Both peptone and YE contain high protein concentrations, determined as 98 and $52 \%[\mathrm{w} / \mathrm{w}]$, respectively, (Figure 2D) (these are estimates as non-protein substances can interfere with the Lowry reaction in complex mixtures). The inactivating effect was then examined with purified proteins (Figure 2C). Lysozyme and bovine serum albumin (BSA) inactivated EW at a concentration range similar to peptone and $\mathrm{YE}(0.5-1 \mathrm{mg} / \mathrm{mL})$ but achieved a more complete inactivation $\left(\sim 100 \%\right.$ inactivation at $1 \mathrm{mg} \mathrm{mL}^{-1}$ BSA or lysozyme). With peptone and $\mathrm{YE}$, colony formation by surviving spores was delayed by up to 4-5 additional days compared to control growth without treatment, whereas with BSA or lysozyme, most colonies were small but visible after the usual 2 days growth period.

To dissect protein constituents that may contribute to EW inactivation, the effects of the protein building blocks, amino acids, were tested. To compare their effects, the amino acid concentrations necessary to inactivate EW were determined at an EW concentration that, on its own, results in $>3 \mathrm{log}$ reduction of $A$. niger spores (360-400 $\left.\mathrm{mg} \mathrm{L}^{-1} \mathrm{FAC}\right)$. All 20 tested amino acids supplied at between 5 to $7 \mathrm{mM}$ at least partly inactivated fungicidal EW activity (Figure 2E). The strongest inactivating effects on EW (i.e., at amino acid concentrations lower than $2.5 \mathrm{mM}$ ) were found for tryptophan (Trp), tyrosine (Tyr, for which $2.5 \mathrm{mM}$ was the highest concentration attainable due to low Tyr solubility in water), cysteine (Cys) and methionine (Met). Certain other amino acids [arginine (Arg), histidine (His), asparagine (Asn)] also showed a mild elevation in EW inactivation compared to the remaining amino acids, evident at later time points (Supplementary Figure S4).

\section{Growth With High Methionine Levels Increases Resistance of Yeast to Subsequent EW Treatment}

As certain amino acids were noted above to affect EW activity particularly strongly, it was hypothesized that the cellular 
A
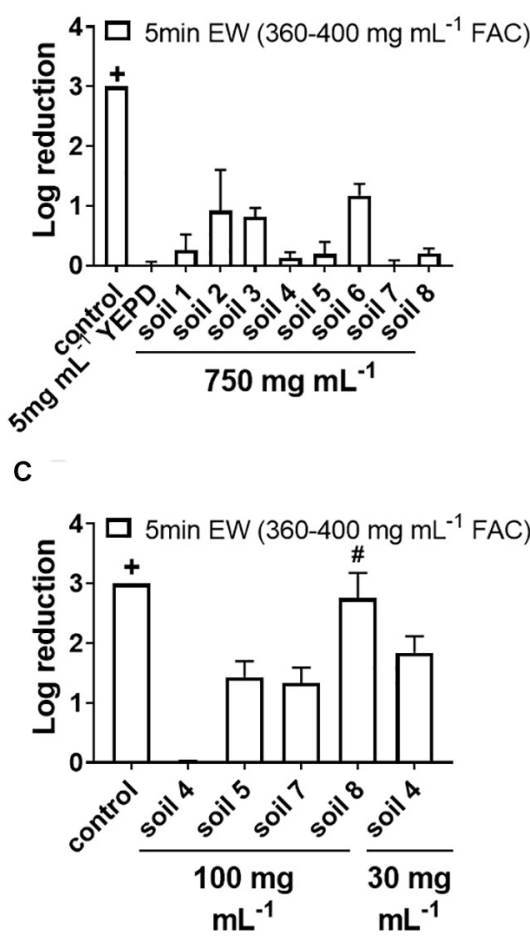

B
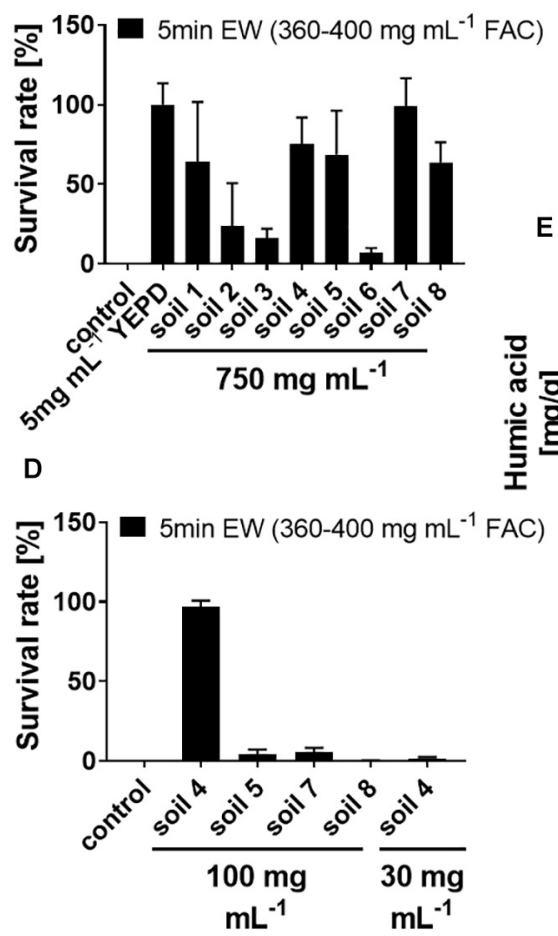

$\mathbf{E}$

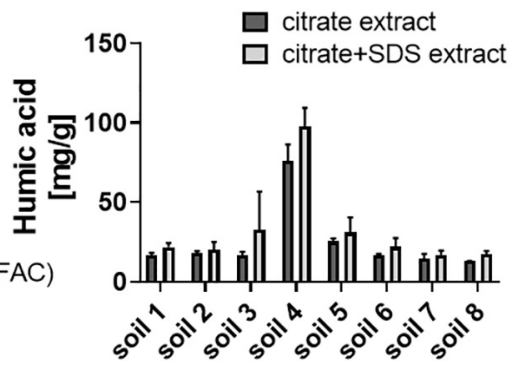

FIGURE 1 | Inactivation of fungicidal EW activity by soil material. Soil (characteristics of soils 1-7 listed in Supplementary Table S1), YEPD or water (control) were added as indicated to EW (400-450 mg L ${ }^{-1}$ FAC) and incubated for 5 min, before exposing A. niger spores to the (soil-supplemented) EW for 5 min, final concentration 360-400 $\mathrm{mg} \mathrm{L}^{-1}$ FAC. For each experiment, log reduction rates (A,C) and survival rates (B,D) were calculated from counts of colony growth on YEPD agar after up to 3 days. (A,B) Soil added to a final concentration of $750 \mathrm{mg} \mathrm{mL}^{-1}$. (C,D) Soil added to final concentrations of 100 or $30 \mathrm{mg} \mathrm{mL}^{-1}$. Data are means \pm SD from at least three biological replicates (except soil 8 in A,B: $n=2)$. The log reduction was $>3$ in control samples (+, no cfu detected when plating 2000 spores). In panels (C,D) there was > 3 log reduction with soil 8 in two out of three biological replicates (\#). (E) Organic compounds were extracted using methods with either citrate or citrate + SDS and the organic contents in the extracts measured as humic acid using a modified Lowry assay (Redmile-Gordon et al., 2013). Data are means \pm SD from two technical replicates.

content of these amino acids might influence resistance of cells to the killing action of EW activity. This was tested first by supplying higher levels of these amino acids to cells for defined incubation periods followed by removal of any remaining extracellular amino acid before the EW treatment. This was to avoid chemical inactivation of EW by extracellular amino acids, allowing study of the effect of amino acid accumulated by cells. These experiments were carried out in Saccharomyces cerevisiae because amino acid uptake among the fungi is best characterized in this yeast model, for which appropriate auxotroph strains and other resources are available, allowing more extensive in vivo studies of EW mode of action. Lower EW concentrations $\left(0.5-1 \mathrm{mg} \mathrm{L}^{-1} \mathrm{FAC}\right)$ than in the previous experiments were needed with $S$. cerevisiae to avoid complete killing, so that the fungal response to EW could be studied (see Supplementary Figure S2B for dosedependent yeast survival after EW treatment). Survival of $S$. cerevisiae was estimated as recovery by culturing cells in broth after EW treatment and determining the y-intercept of the exponential phase as an estimate for the starting viable-cell density (see section "Materials and Methods" and
Supplementary Figure S1). Exogenously supplied amino acids can be readily taken up by yeast cells. Pre-culture of yeast for 4-5 $\mathrm{h}$ in defined medium (YNB) supplemented with different amino acids $(0.3 \mathrm{mM})$, followed by EW treatment in the absence of amino acids, revealed a protective effect of methionine (Figure 3A). Pre-culture with Met increased recovery after EW treatment by $>1.5$-fold (FDR adjusted $p=0.0242)$. Other amino acids chosen based on the EW inactivation results above (Trp, Tyr, Arg, His, and Asn) did not exhibit a protective effect (Arg and Tyr actually gave slight sensitization). Pre-culture with Cys supplement inhibited yeast growth so it could not be tested (data not shown). Pre-culture with $\mathrm{N}$-acetyl-cysteine (NAC), commonly used as a Cys precursor, did not inhibit yeast growth but did not protect against EW (Figure 3B). The protective effect of Met was not dependent on the Met auxotrophy (biosynthetic defect demanding externally supplied Met) of the $S$. cerevisiae BY4741 laboratory strain used above, as the isogenic Metprototrophic strain S. cerevisiae BY4742 was also protected by Met pre-treatment (Figure 3C). Furthermore, deletion strains auxotrophic for $\operatorname{Trp}(\operatorname{trp} 1 \Delta), \operatorname{Arg}(\arg 4 \Delta)$ or His (BY4741: 


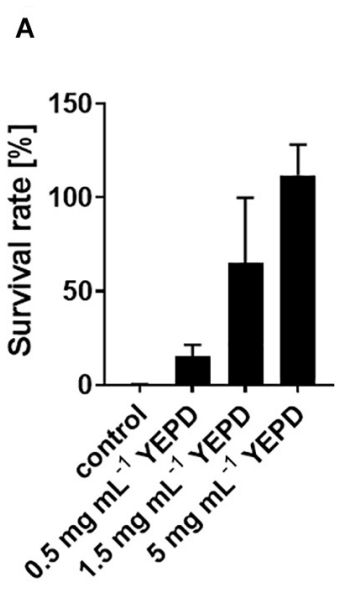

$$
\text { B }
$$

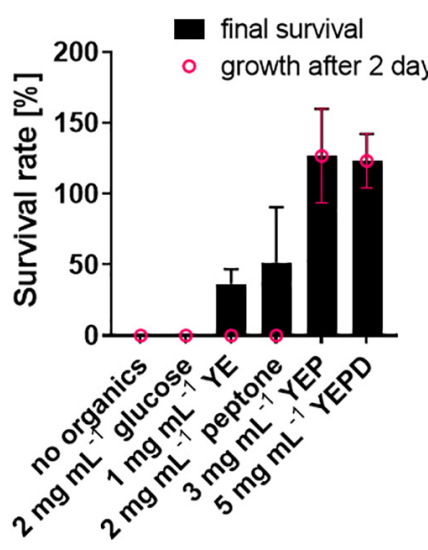

D

\begin{tabular}{|c|c|c|c|}
\hline & YEP & Peptone & YE \\
\hline $\begin{array}{c}\text { protein } \\
\text { concentration } \\
(\mathrm{w} / \mathrm{w})[\%]\end{array}$ & $82 \pm 6$ & $98 \pm 23$ & $52 \pm 4$ \\
\hline
\end{tabular}

E

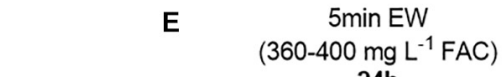

$24 \mathrm{~h}$

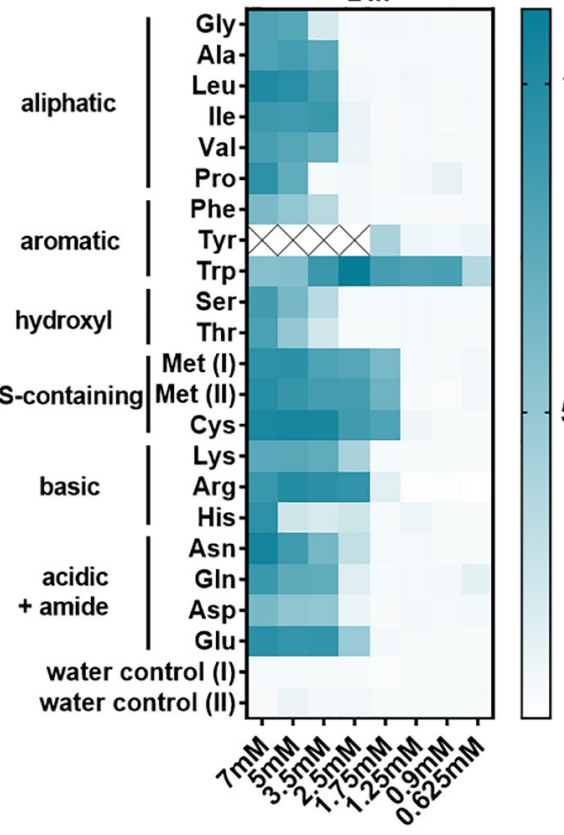

100

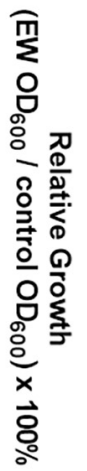

FIGURE 2 | Inactivation of fungicidal EW activity by proteins and amino acids. (A-C) Organics were included at the indicated concentrations in EW preparations (360-400 mg L ${ }^{-1}$ FAC) used to treat $A$. niger spores. (A) YEPD [consisting of peptone (40\% [w/w] of the dry weight), yeast extract (20\%), glucose (40\%)], (B,C) YEPD components (YE, yeast extract; YEP, YE + peptone; YEPD, YEP + glucose) and (C) pure proteins. The organics were added 5 min prior to use of the EW for short-exposure (A, $1 \mathrm{~min}$; B,C, 6 min) treatments of spores. Survival rates were determined by colony counts on YEPD agar. Values shown are means from biological triplicates $\pm \mathrm{SD}$. Appearance of colonies was delayed after some treatments, as indicated where \% survival after up to a week (black) is greater than from counts at 2 days (pink; growth was at $28^{\circ} \mathrm{C}$ for the first 2 days and then at RT). (D) Protein concentrations in YEP components are means from technical triplicates \pm SD. (YEP comprised $66.7 \%$ peptone and 33.3\% YE, reflecting the relative compositions of these components in YEPD medium). (E) Amino acids were included at the indicated concentrations in EW used to treat $A$. niger spores, performed as in A-C. Subsequent growth was determined in YEPD broth by $\mathrm{OD}_{600}$ readings after $24 \mathrm{~h}$ and normalized to control growth without EW treatment. Mean values are shown from biological triplicates (except lysine, where $n=2$ ). Within each replicate experiment, assays were split across two 96-well plates, both of which contained Met as an internal control, shown as Met(I) and Met(II). Tyrosine values $\geq 2.5 \mathrm{mM}$ are missing due to limited water solubility. Numerical values and standard deviations are listed in Supplementary Table S2.

met15 $\Delta$, his $3 \Delta$ ), and the partial alanine auxotroph alt1 $\Delta$ (Ala did not have a particularly strong EW inactivation effect [see previous section] and was used as a control amino acid), were not protected by their respective amino acid (Figure 3A and Supplementary Figure S5).

Because EW is likely to contain different active species, we tested whether the observed effect of Met pre-culture on resistance to EW (Figures $3 \mathbf{A}-\mathbf{C}$ ) was mimicked with $\mathrm{NaOCl}$ treatment. Similar to EW, pre-culture with Met gave increased resistance to $\mathrm{NaOCl}$ treatment (Figure 3D). Like EW, ozonated water was produced using an electrolysis technology but, unlike EW, it does not contain FAC. In water, ozone reacts to form other reactive species such as highly reactive hydroxyl radicals (Wang et al., 2020). Recovery after ozonated water treatment was also increased after Met pre-culture (Figure 3E). The results indicate that Met may protect against both chlorine and non-chlorine active species in EW.

\section{The Protective Effect of Met Pre-culture Is Probably Not Due to a Downstream Product of Met Metabolism}

All cellular life relies on L-isomers of amino acids, and we confirmed that $S$. cerevisiae BY4741 is unable to grow on D-Met as the sole Met source, while growth in medium containing L-Met was not affected by D-Met addition (Supplementary Figure S6). Adding D-Met to medium containing L-Met $(0.13 \mathrm{mM})$ to a total of $0.3 \mathrm{mM} \mathrm{Met}(\mathrm{D}+\mathrm{L})$ did not mimic 


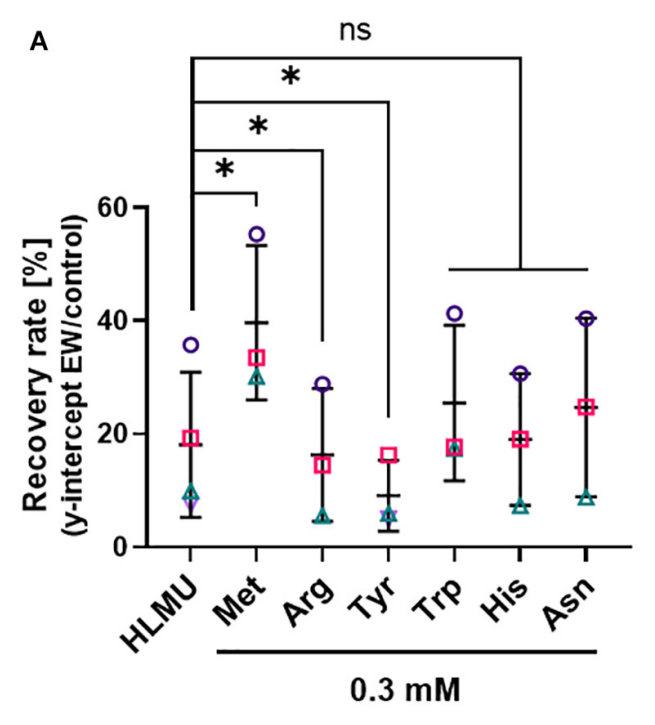

D
B

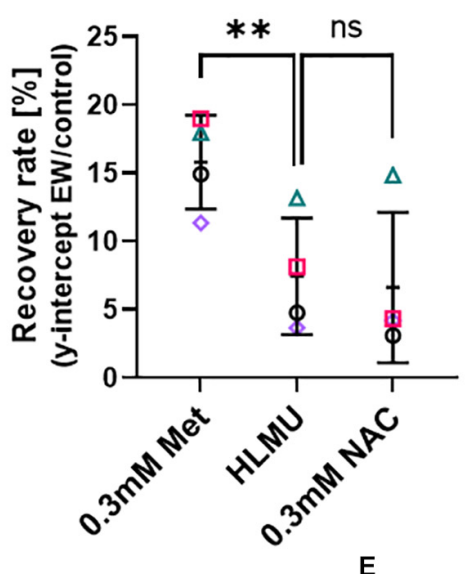

C

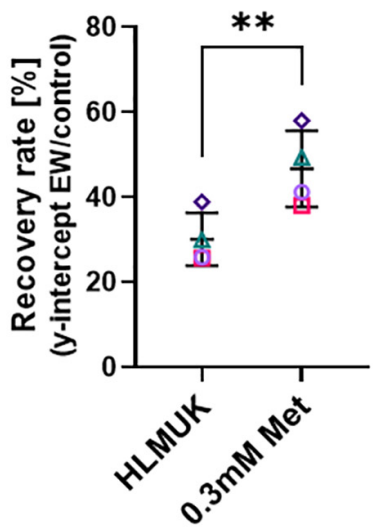

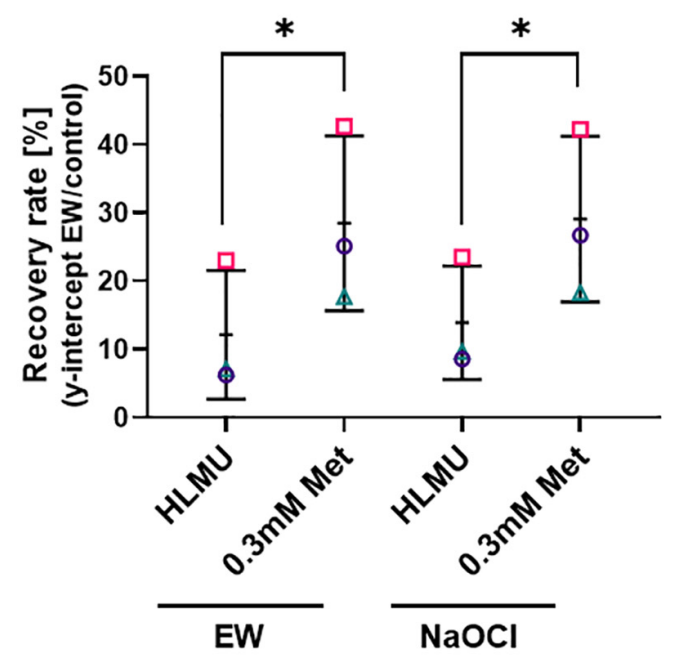

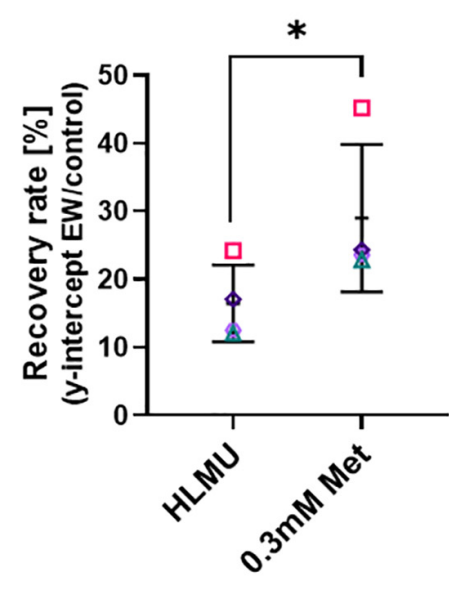

ozonated water

FIGURE 3 | Influence of cellular methionine on recovery of cells after EW, $\mathrm{NaOCl}$ and ozonated water treatments. Survival of yeasts after treatment was estimated by subsequent recovery in YEPD broth (see section "Materials and Methods" and Supplementary Figure S1). (A-C) Treatment with EW (0.5-1 mg L ${ }^{-1}$ FAC, 5 min). (D) Treatment for 5 min either with EW or NaOCl, in parallel, both oxidants at $0.7 \mathrm{mg} \mathrm{L}^{-1}$ FAC. (E) Treatment with ozonated water, used within 2 min of generation for a 5 min treatment. Data are shown only for experiments where recovery was $>10 \%$, to minimize the influence of technical variation that was observed in response to ozonated water stress. (A-E) S. cerevisiae BY4741 (A,B,D,E) or BY4742 (C) were pre-cultured with amino acids at the indicated total concentrations for 4-5 h prior to treatment; control growth and pre-culture were in YNB broth also containing 0.1338 mM Met, $0.129 \mathrm{mM} \mathrm{His,} 0.763 \mathrm{mM}$ Leu, $0.178 \mathrm{mM}$ Ura (HLMU, A,B,D,E), plus $0.21 \mathrm{mM}$ Lys for BY4742 (HLMUK, C). Where amino acids were added to the control broth, the pre-culture concentration (0.3 mM) refers to the final total concentration (i.e., including the control-broth content). YNB was buffered (0.1 M potassium phosphate buffer pH 6) in panels (A,B). Cells were washed in water before treatment. NAC, N-acetyl cysteine. All plots: mean values \pm SD are shown for at least three biological replicates, with different replicate experiments distinguished by different symbols. Significant differences versus relevant controls are denoted by $* p<0.05,{ }^{* *} p<0.01$ according to paired $t$-test (two-tailed) with correction for multiple comparisons by controlling the false discovery rate at 5\% FDR (Benjamini et al., 2006). ns, not significant.

the protective effect observed with $0.3 \mathrm{mM} \mathrm{L-Met} \mathrm{in} \mathrm{the} \mathrm{Met-}$ auxotrophic strain BY4741 (Figure 4A). In contrast, adding D-Met to medium free of L-Met for the pre-culture of the Met prototroph strain BY4742 resulted in a protective effect; the effect of D-Met was actually larger than the effect of L-Met pre-culture (Figure 4B). There could be increased D-Met uptake in medium free of L-Met due to a lack of competition for Met uptake systems (such as Mup1) in the absence of L-Met (Gits and Grenson, 1967). This protective effect of the metabolically inactive D-Met suggests a direct role of Met itself in EW resistance.

Saturation of Met uptake is reported to occur within $10 \mathrm{~min}$ of Met addition to Met-free medium (Schwabe and Bruggeman, 2014), and downregulation of high-affinity Met uptake systems in response to high Met also commences within 10 min (Menant et al., 2006). Here, $10 \mathrm{~min}$ L-Met pre-culture was sufficient to increase resistance of yeast to EW, and longer Met pre-treatments did not add further advantage (Supplementary Figure S7). 

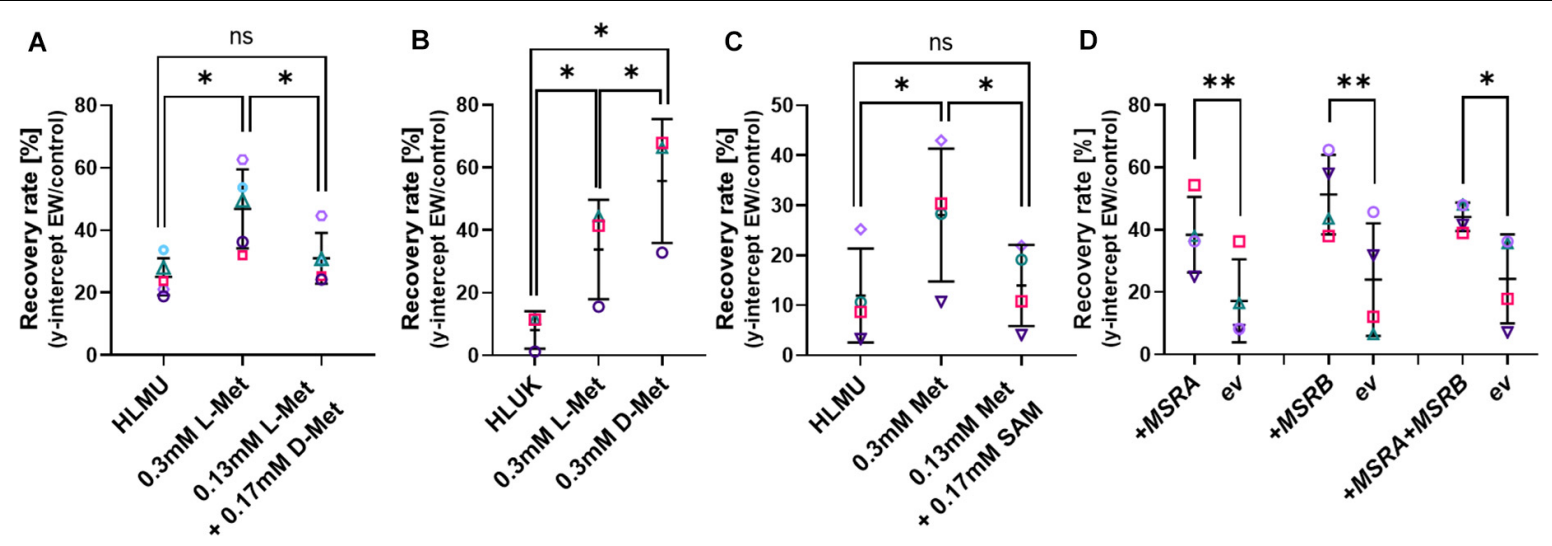

FIGURE 4 | Influence of methionine isomers, SAM and MetO-reduction on recovery of cells after EW treatment. Survival of yeasts after EW treatment (0.5-1 mg $L^{-1}$ FAC, 5 min) was estimated by subsequent recovery in YEPD broth (see section "Materials and Methods" and Supplementary Figure S1). (A-C) Pre-culture of S. cerevisiae BY4741 (A,C) or BY4742 (B) with L-Met, D-Met or S-adenosyl-methionine (SAM) at the indicated total concentrations for 4-5 h prior to EW treatment; control growth and pre-culture were in YNB broth also containing 0.1338 mM Met, 0.129 mM His, 0.763 mM Leu, 0.178 mM Ura (HLMU, A,C), or 0.21 mM Lys instead of Met for BY4742 (HLUK, B). Where amino acids were added to the control broth, the pre-culture concentration (0.3 mM) refers to the final total concentration (i.e., including the control-broth content). YNB was buffered (0.1 M potassium phosphate buffer pH 6) in C. Cells were washed in water before EW treatment. (D) Overexpression of MSRA and MSRB in multicopy vectors YEp351 and YEp352, respectively (ev, empty vector), in S. cerevisiae BY4741. All plots: mean values $\pm \mathrm{SD}$ are shown for at least three biological replicates, with different replicate experiments distinguished by different symbols. Comparisons of interest were tested by paired $t$-test (two-tailed) with correction for multiple comparisons by controlling the false discovery rate at $5 \%$ FDR (Benjamini et al., 2006$) .{ }^{*} p<0.05$; ** $p<0.01 ;$ ns, not significant.

The first step of downstream methionine metabolism yields S-adenosyl-methionine (SAM). Pre-treatment with SAM did not improve resistance to EW, further supporting a role of Met itself in protection, rather than a Met metabolic product (Figure 4C). SAM uptake and utilization was confirmed by the restoration of growth of S. cerevisiae BY4741 in Met-free, SAM-supplemented medium (Supplementary Figure S6).

\section{The Protective Effect of Methionine May Arise From Oxidation of Reduced Met by the FAC in EW}

Methionine residues can be naturally oxidized to methionine sulfoxide (MetO) but can be reduced back to methionine by cellular methionine sulfoxide reductases, encoded by MSRA, $M S R B$, and $f R M S R$ in yeast. It was hypothesized that Met oxidation by EW could explain the above protective effects on cells of adding Met in its reduced form, suggesting a potential role of accumulated Met as a direct ROS scavenger in EW stress. Accordingly, improved maintenance of reduced Met by MSR activity should also increase resistance to EW. The yeast MSRA and MSRB enzymes were overexpressed on multicopy plasmids as characterized previously (Sumner et al., 2005), either alone or in combination. In all cases, resistance of yeast to EW was significantly increased by elevated MSR expression (Figure 4D), indicating that the level of reduced Met specifically is important for resistance to EW.

Methionine might be directly oxidized by EW, with simultaneous depletion of oxidizing species in EW. The oxidizing properties of EW were assayed with the oxidation-sensitive fluoroprobes HPF and APF. These probes enable the distinction between FAC $\left({ }^{-} \mathrm{OCl} / \mathrm{HOCl}\right)$ and other $\mathrm{ROS}$ (mainly ${ }^{\bullet} \mathrm{OH}$ and
$\mathrm{ONOO}^{-}$). While the reactivity of APF and HPF with other ROS is of a similar order (albeit up to $5 \mathrm{x}$ stronger with APF), APF reactivity with FAC is up to $600 \times$ stronger than HPF (Setsukinai et al., 2003). HPF fluoresces strongly only at $\geq 5$-fold excess of FAC (Flemmig et al., 2012). To test selective detection of FAC with APF but not HPF, equimolar levels of probe and oxidant were used ( $5 \mu \mathrm{M}$ probe; the FAC of EW would correspond to $\sim 5.5 \mu \mathrm{M} \mathrm{HOCl}$ at $\sim 0.3 \mathrm{mg} \mathrm{L}^{-1}$ FAC). Only APF was fluorescent at these levels, whereas EW concentrations $\geq \sim 1.5 \mathrm{mg} \mathrm{L}^{-1}$ FAC resulted in both APF and HPF fluorescence (Figure 5A). A similar pattern was observed for diluted $\mathrm{NaOCl}$ (Figure 5D), indicating that the FAC might be (one of) the main oxidizing agent(s) in the EW. Other ROS probes were tested but resulted either in no signal (DHE) or no signal at equimolar levels of probe and oxidant $\left(\mathrm{H}_{2} \mathrm{DCFDA}\right.$; when mixed with undiluted $\mathrm{EW}$, an unstable fluorescence signal was obtained that decreased within minutes, indicating potential oxidative damage to the probe at high FAC; not shown).

The amino acids His, Ala, Arg, Asn, Trp, Met, and Cys (chosen based on a stronger EW inactivation effect compared to other amino acids, see Figure 2E, plus Ala as a negative control) were added to the EW and $\mathrm{NaOCl}$ oxidant solutions, to test effects on APF oxidation. Only methionine and cysteine (at $1.2 \mu \mathrm{M}$ ) produced significant decreases in the APF-oxidizing properties of either $\mathrm{EW}$ or $\mathrm{NaOCl}$ (Figures 5B,E). Because the work described above indicated that L-Met (reduced) was more important for increased resistance of yeast to EW than MetO (oxidized Met, substrate of MSR enzymes) but not D-Met, these molecules were compared also for effects on APF oxidation by $\mathrm{EW}$ and $\mathrm{NaOCl}$ (Figures 5C,F). L-Met and D-Met resulted in an equally strong suppression of the oxidizing properties of both $\mathrm{EW}$ and $\mathrm{NaOCl}$, consistent with the mediation of a protective effect in yeast by 


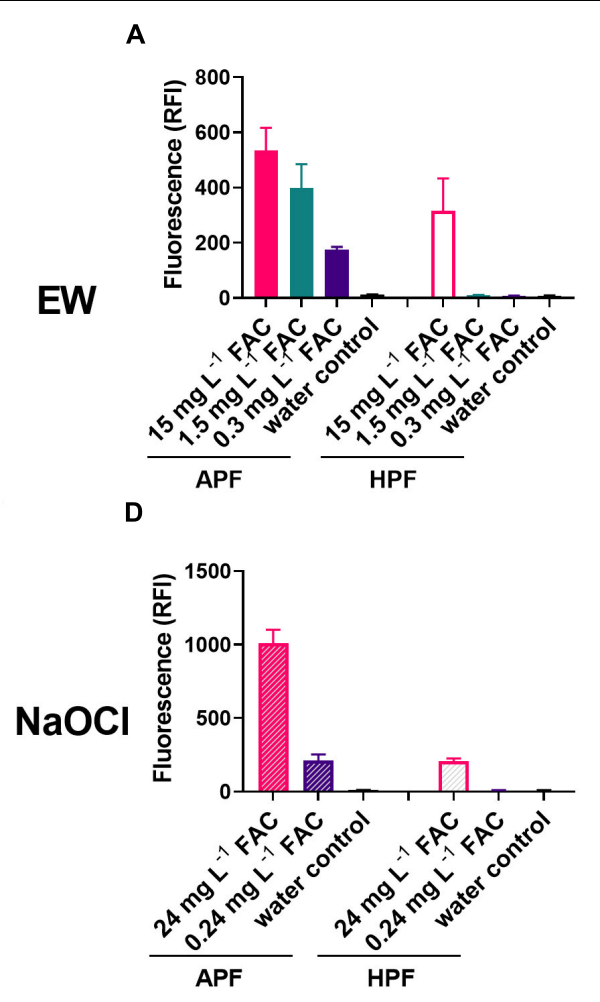

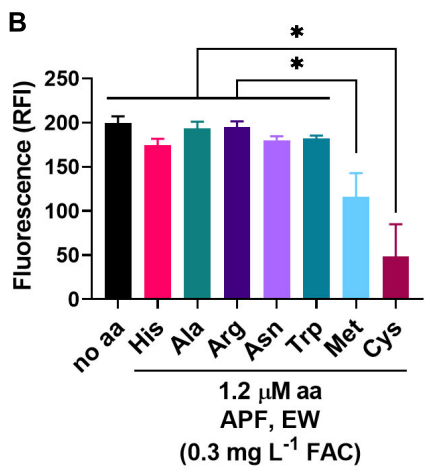

E

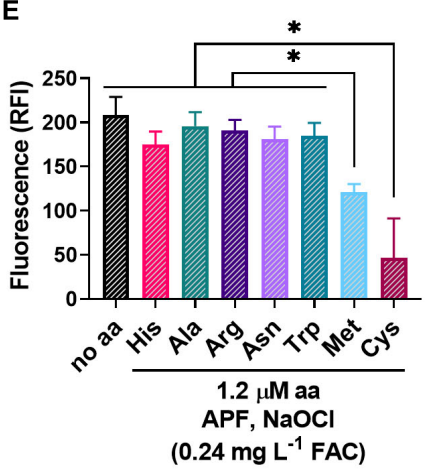

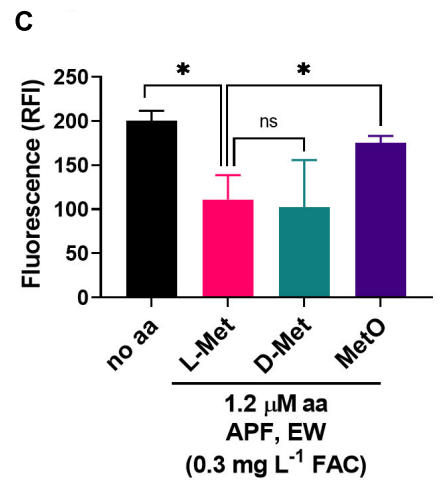

$\mathbf{F}$

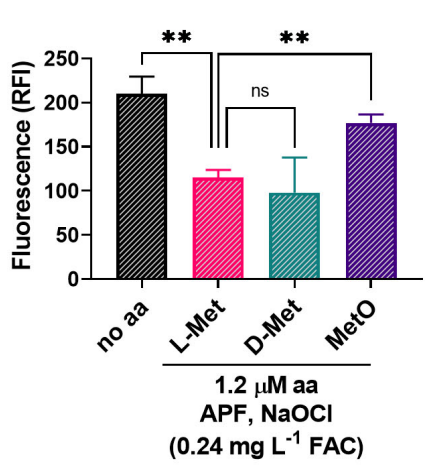

FIGURE 5 | Influence of amino acids on the oxidizing properties of EW and $\mathrm{NaOCl}$ (A,D) The fluorescent ROS probes APF and HPF (5 $\mu$ M) were mixed with different dilutions of EW (A) or $\mathrm{NaOCl}$ (D) $\left[100 \%\right.$ (v/v) EW $=1.8-2.0 \mathrm{~g} \mathrm{~L}{ }^{-1} \mathrm{FAC} ; 100 \% \mathrm{NaOCl}=3.0-3.1 \mathrm{~g} \mathrm{~L}^{-1} \mathrm{FAC}$. Fluorescence (RFI, relative fluorescence intensity) was recorded within 2 min of mixing. B,C,E,F) The effect of amino acids $(1.2 \mu \mathrm{M})$ present in the APF-oxidant mix on the fluorescence signal was tested at approximately equimolar concentrations of dye $(5 \mu \mathrm{M})$ and $\mathrm{EW}\left[\sim 0.3 \mathrm{mg} \mathrm{L}{ }^{-1} \mathrm{FAC} \sim 5.5-6.1 \mu \mathrm{M} \mathrm{HOCl}(\mathrm{FAC}\right.$ expected to be primarily $\mathrm{HOCl}$ ); $\mathbf{B}, \mathbf{C}]$, or $\mathrm{NaOCl}$ $\left[\sim 0.24 \mathrm{mg} \mathrm{L}^{-1}=3.2-3.3 \mu \mathrm{M} ; \mathbf{E}, \mathbf{F}\right]$. Mean values $\pm \mathrm{SD}$ are shown for at least three biological replicates. ${ }^{*} p<0.05, * * p<0.01$, ns, not significant; according to paired $t$-test (two-tailed) with correction for multiple comparisons by controlling the false discovery rate at 5\% FDR (Benjamini et al., 2006).

either isomer (Figure 4B). MetO had a weaker effect on APF oxidation by EW and $\mathrm{NaOCl}$, in keeping with a model in which oxidation of Met to MetO by EW or $\mathrm{NaOCl}$ quenches additional oxidation of APF.

In contrast to EW, ozonated water produced similar fluorescence responses with APF and HPF (Figure 6A). Met and Cys could suppress these oxidizing actions of ozonated water, but this required higher concentrations of the amino acids $(10 \mu \mathrm{M})$ than for EW inactivation $(1.2 \mu \mathrm{M}$ ) (Figures 6B,C). At $10 \mu \mathrm{M}$ amino acid, fluoroprobe oxidation by EW was fully inactivated by Met and Cys and partially inactivated by Asn (Figure 6D). These results suggest a lower reactivity of the amino acids with ozonated water compared with EW (Figures 5, 6). The strong reactivity of EW with Met and Cys suggests that the FAC, as opposed to other potential ROS components of EW, is likely to be the main EW component reacting with these amino acids.

\section{EW Treatment Affects FeS Cluster Proteins}

Methionine in its oxidized state has previously been reported to increase oxidative damage to iron-sulfur clusters (Sideri et al., 2009). We hypothesized that the protection against EW by reduced-Met observed here could be related to the maintenance of FeS protein function. Protein extracts from yeast were exposed to EW, with primaquine treatment serving as a positive control as this drug is known to target FeS clusters (Lalève et al., 2016). Relative activity of the FeS cluster protein aconitase (normalized to fumarase activity) was decreased by $\sim 70 \%$ in EW treated extracts (Figure 7A; absolute activities are shown in Supplementary Figure S8; fumarase is also a citric acid cycle enzyme but does not contain an FeS cluster). As fumarase activity was not significantly affected by EW (Supplementary Figure S8), aconitase only was assayed in further in vitro experiments, at standardized protein-extract additions. Adding Met or Cys to the in vitro $\mathrm{EW}$ treatments suppressed the strong inhibition of aconitase activity by EW (Figure 7B).

To test whether similar effects could be detected during in vivo EW treatment of yeast cells, an EW dilution yielding $>80 \%$ cell viability (according to cfu counts) was used to avoid nonspecific effects due to lethality. Enzyme assays with protein extracts obtained from the EW-treated cells revealed a $22 \%$ decrease in relative aconitase activity $(p=0.0425)$ (Figure 7C). A different FeS protein, the essential Rli1 protein, has roles in critical cellular functions such as translation, ribosome biogenesis and recycling (Kispal et al., 2005; Schuller and Green, 2017). It is an important target of oxidative stress due to impaired supply of the FeS-cofactor to the protein under oxidative stress 

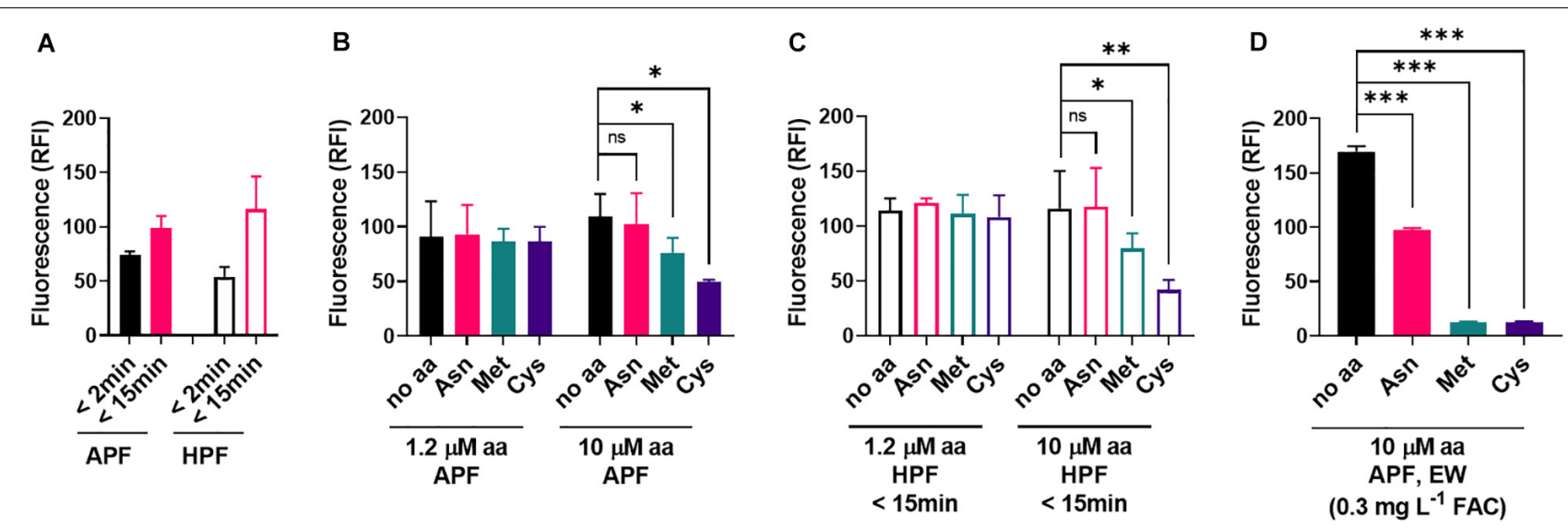

FIGURE 6 | Influence of amino acids on the oxidizing properties of ozonated water. (A) The fluorescent ROS probes APF and HPF (5 $\mu$ M) were mixed with ozonated water. Fluorescence (RFI, relative fluorescence intensity) was recorded within 2 min of mixing and again 13 min later. (B,C) Effects of amino acids supplied at the specified concentrations in the APF-ozonated water mix (B) or HPF-ozonated water mix (C). Because HPF fluorescence strongly increased within the first few minutes, and no significant effect of the amino acids was visible at the first time point (<2 min), data for the 15 min time point are shown for HPF. (D) Effect of high amino acid concentrations (10 $\mathrm{MM}$ ) supplied in an APF-EW mix (experimental details as described in Figure 5). Mean values \pm SD are shown for at least three biological replicates. ${ }^{*} p<0.05,{ }^{* *} p<0.01,{ }^{* * *} p<0.001$, ns, not significant; according to paired $t$-test (two-tailed) with correction for multiple comparisons by controlling the false discovery rate at 5\% FDR (Benjamini et al., 2006).

conditions, and Rli1 overexpression in yeast increases resistance to pro-oxidants (Alhebshi et al., 2012). Overexpression of Rli1 increased yeast resistance to EW (Figure 7D). In contrast, overexpression of a different essential FeS-protein, Yah1, did not reproducibly increase resistance to EW, consistent with the reported phenotype of this particular overexpression strain under pro-oxidant stress (Vallières et al., 2017). The results suggest that FeS cluster proteins are an important cellular target of EW action.

\section{DISCUSSION}

Sanitizers are vital products for managing microbial contamination in diverse applications, including in food processing, medical facilities, water treatment and, increasingly, personal use (Huang et al., 2008; Gil et al., 2015). Key considerations determining sanitizer efficacy in particular uses include: (a) the potential for incidental dampening of activity, e.g., by contaminating organic matter, and (b) the mode of antimicrobial action, so potential resistance among target microorganisms can be understood and anticipated. The top-down approach that we introduced here, with the sanitizer EW, enabled us to shed new light on both these key aspects; so providing comprehensive new understanding of EW action and efficacy. Our findings that incidental protein and particular amino acids strongly affect the fungicidal EW activity then led us to new understanding of the oxidizing mode of EW action, in which reduced-methionine of cells plays a critical role.

In the case of processing applications relevant to the food industry, sanitation may be influenced by soil and complex organic mixtures derived from fresh produce or processing and irrigation water. It has previously been reported that different complex organics (peptone, glycine, milk, minced meat, chopped cabbage, and river natural organic matter) can react with the
FAC in EW, depleting the FAC and forming combined chlorine with lower sanitation activity compared to FAC (Oomori et al., 2000; Ogunniyi et al., 2019). Combined chlorine compounds such as chloramines (from reaction of FAC with amines) can retain mild oxidizing activity (Hawkins et al., 2003). This highlights the importance of survival-based tests compared to FAC analysis for a more complete assessment of EW efficacy. In this study, survival was assessed by recovery in complex media, meaning that sublethal damage to cells and spores cannot be ruled out, previously reported for EW treatments (Lan et al., 2019). This may partly explain the growth delay observed after EW treatment in some conditions (Figure 2).

Unexpectedly large additions of soil were needed to decrease the fungicidal activity of EW in this study, although this resonates with the high levels of $\mathrm{NaOCl}(6 \%)$ used to remove organic compounds from soil samples (Margenot et al., 2015). This indicates that EW can be used for sanitization in the presence of moderate levels of soil, or even for the sanitization of soil samples (Harvey et al., 2020). Reactive oxygen species can be scavenged in soil by plant-derived tannins and other phenolic compounds (Rimmer, 2006). The FAC, hydrogen peroxide or other ROS present in EW could be inactivated after direct oxidation of soil organics, or reaction with inorganic metal species [hydroxyl radical formation involving $\mathrm{H}_{2} \mathrm{O}_{2}$ (Fenton chemistry) or $\mathrm{HOCl}$ ], could lead to further reactivities with aromatic and other organic compounds (Mikutta et al., 2005; Panasenko et al., 2013). Accordingly, the soil type with the highest organics content in this study (a sandy clay loam soil) had the strongest inactivating effect on EW. Its high organics content was supported both by analyses performed here, as well as a higher loss-on-ignition value (LOI, an indicator of soil organic matter) (Supplementary Table S1). Previously, the bactericidal activities of EW and $\mathrm{NaOCl}$ were reported to be inactivated to a similar extent by complex natural organics (Ogunniyi et al., 2019). While certain soil organics are 
A

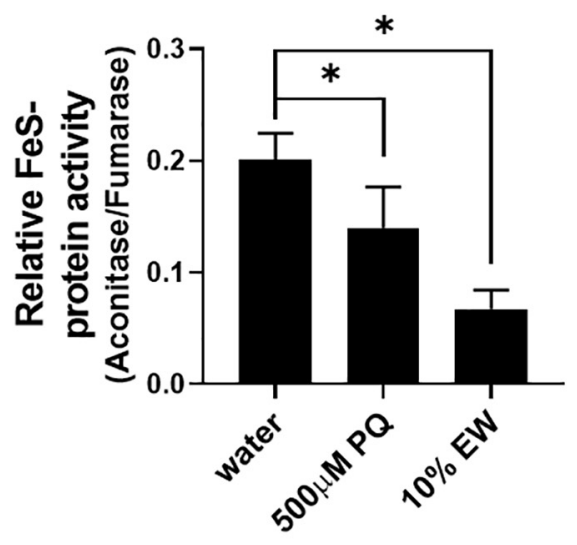

C

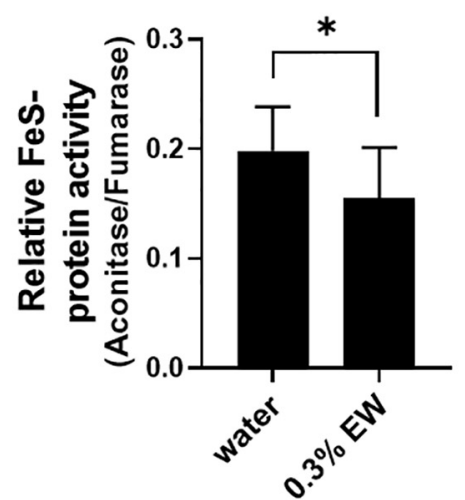

B

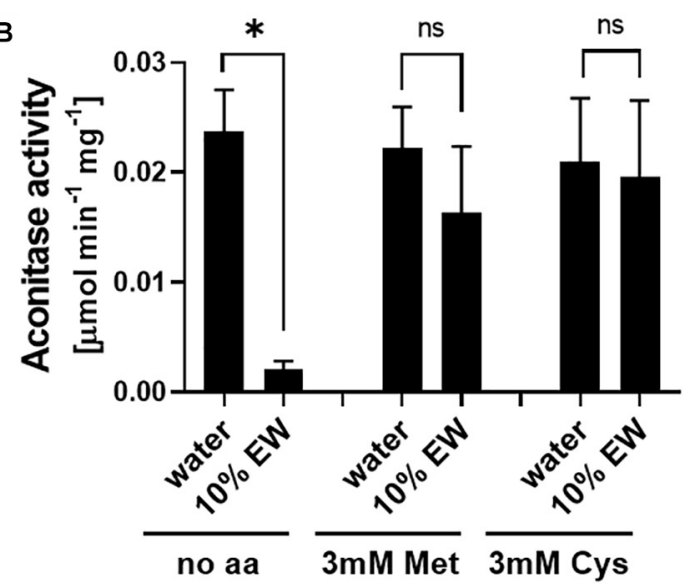

D

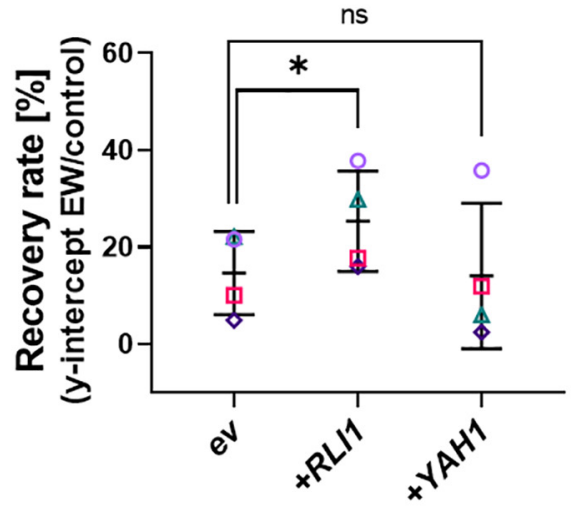

FIGURE 7 | Relationship between EW action and FeS protein activity. (A) Crude protein extracts from exponentially growing S. cerevisiae BY4741 cells were treated in vitro with $500 \mu \mathrm{M}$ primaquine (PQ), 10\% EW [v/v] (180-200 $\mathrm{mg} \mathrm{L}^{-1} \mathrm{FAC}$ ) or water (control) for $20 \mathrm{~min}$, before determination of aconitase and fumarase activities. Aconitase activity is normalized to fumarase activity (a non-FeS protein); for absolute activities, see Supplementary Figure S8. (B) Aconitase activity of in vitro treatments performed as in panel (A) but with inclusion of $3 \mathrm{mM}$ Met or Cys added to protein extracts shortly before EW exposure. (C) In vivo EW treatment (0.3\% EW: 5.4-6 mg L ${ }^{-1}$ FAC) of exponentially growing yeast cells followed by protein extraction and determination of enzyme activities (the dense yeast suspensions needed for sufficient protein yield required a higher \% EW here for comparable effect to other in vivo treatments in this study). (D) Overexpression of the essential FeS proteins RLI1 or YAH1 from vector pCM190 (ev, empty vector) in S. cerevisiae BY4741. Survival of yeasts after EW treatment $\left(0.5-1\right.$ mg L ${ }^{-1}$ FAC, 5 min) was estimated by subsequent recovery in YEPD broth (see section "Materials and Methods" and Supplementary Figure S1). Mean values \pm SD are shown for at least three biological replicates, with different replicate experiments distinguished by different symbols in panel (D). ${ }^{*} p<0.05$, ns, not significant; according to paired $t$-test (two-tailed) with correction for multiple comparisons by controlling the false discovery rate at 5\% FDR (Benjamini et al., 2006).

targets of $\mathrm{NaOCl}$ (sterols, long-chained lipids, lignin dimers), other soil compounds are less reactive (Sleutel et al., 2009). The latter finding was explained by potential protective effects by the soil minerals and structure that may shield molecules such as peptides from $\mathrm{NaOCl}$ exposure. Interestingly, a moderate (but not significant) correlation between decreasing particle size and EW activity (spore inactivation) was apparent for the soil samples tested here [Pearson's $r$ values for spore survival versus silt (smaller) or sand (larger) particles were 0.48 or -0.52 , respectively]. This is consistent with less shielding of cells or molecules in smaller particles. It is clear from the results that some fungicidal activity of EW persisted at moderate levels of soil contamination, although this could be coincident with the formation of by-products of concern, such as trihalomethanes (THMs) from the reaction of soil organics with the FAC (Jackman and Hughes, 2010).
Previously, partial or full inactivation of EW occurred over a wide concentration range for different organics (0.04-100 g $\mathrm{L}^{-1}$ ) (Oomori et al., 2000; Jo et al., 2018; Ogunniyi et al., 2019), underscoring the need to understand further EW reactivity with different chemical components of complex organic mixes. Inactivation of the FAC and the bactericidal activity of EW (31$50 \mathrm{mg} \mathrm{L}^{-1} \mathrm{FAC}$ ) has been reported in $0.1-1 \mathrm{~g} \mathrm{~L}^{-1}$ peptone (Oomori et al., 2000; Jo et al., 2018), and we found comparable reactivity of the present EW (360-400 $\mathrm{mg} \mathrm{L}^{-1}$ FAC) with $\sim 1 \mathrm{~g} \mathrm{~L}^{-1}$ peptone, yeast extract or pure proteins, according to fungicidal activity. As proteins are highly abundant in all living organisms and in many foods or as surface-contaminants, these are important considerations for EW applications.

The reactivity of protein components with FAC ( $\mathrm{HOCl} /{ }^{-} \mathrm{OCl}$, at $\mathrm{pH} 7.4$ ) is reported to decrease in the order: Cys $>$ Met $>$ cystine $\approx$ His $\approx \alpha$-amino group (in free amino 
acids) $\approx$ terminal amino group (in proteins) $>$ Trp $>$ Lys $>$ Tyr $\approx$ Arg $>$ backbone amides $>$ Asn $\approx$ Gln (Pattison and Davies, 2001; Storkey et al., 2014). Here, amino acids with the strongest EW-inactivation effects were Met, Cys, His, Trp, Tyr, Arg, and Asn, with Met and Cys found to suppress most strongly the oxidizing properties of EW and $\mathrm{NaOCl}$. The results were in close agreement with the reactivity data for FAC, suggesting that FAC in EW could at least partly account for EW reactivity with (and inactivation by) protein and amino acids. Non-chlorine products of electrolysis were tested here by using ozonated water. Amino acid reactivity of ozone is reported as Cys $>\operatorname{Trp} \approx$ Met $>$ Phe $\approx$ His (Sharma and Graham, 2010). The rate constants for Cys and Met reactivity with ozone are of the order $10^{6} \mathrm{M}^{-1} \mathrm{~s}^{-1}$ $(\mathrm{pH}$ 8) whereas reactivities of Met and Cys with FAC are of the order $10^{7}-10^{8} \mathrm{M}^{-1} \mathrm{~s}^{-1}$ ( $\left.\mathrm{pH} 7.4\right)$ (Storkey et al., 2014). This supports the present data, indicating that Met and Cys have greater effects with $\mathrm{NaOCl}$ and EW than with ozonated water, consistent with a primary role for the FAC in the reactivity of EW with these amino acids.

Several amino acids are known to be especially prone to oxidation, such as Pro, Arg, Lys, Thr, Trp, Phe, Tyr, Cys, and Met (Baraibar et al., 2013). However, the data presented here on EW reactivity and amino acids matches better the specific reactivities of FAC (we observed little particular effect with Pro, Lys, Thr or Phe). While non-chlorine ROS may contribute to the antimicrobial effect of EW, a major role is less likely in stored EW solutions (as used here) due to the short life time of these ROS (Jeong et al., 2007). Within cells, FAC species may also lead to formation and conversion of other ROS species which arise as respiratory by-products: Hypochlorous acid reacts with superoxide radicals and with iron to form hydroxyl radicals, and with hydrogen peroxide to form singlet oxygen (Panasenko et al., 2013). Hydroxyl radicals are highly reactive and can oxidize most cellular molecules, including all proteinogenic amino acids (rate constants $>10^{7} \mathrm{M}^{-1} \mathrm{~s}^{-1}$ ), the most reactive of which include Met and Cys (>10 $\mathrm{M}^{-1} \mathrm{~s}^{-1}$ ) (Xu and Chance, 2005).

The reaction of FAC with proteins may lead to protein damage (aggregation, fragmentation, misfolding, cross-linking) and sidechain damage (e.g., formation of chloramines, carbonyls), but also to enhanced activity of hypochlorite-responsive chaperone proteins (Pattison and Davies, 2001; Cater et al., 2019). Protein damage after FAC treatment has been reported in diverse cell types (Winter et al., 2008; Carmona-Gutierrez et al., 2013), and metabolome studies revealed that EW affects amino acid levels and associated pathways in bacteria (Liu et al., 2017, 2020), consistent with the high reactivity of EW with amino acids discussed above. The data presented here indicate a potential protective system against EW-induced damage in vivo, involving methionine. Pre-culture with methionine, to allow accumulation of the amino acid, specifically (compared to other amino acids) increased recovery from EW treatment. The effect could be mimicked by the D-Met isomer but not by the first metabolic product of Met utilization (SAM), and occurred rapidly (within 10 min incubation with elevated Met). This suggested a role of the methionine molecule itself in protection against EW. Furthermore, the Met protective effect appeared to extend to a more general form of oxidative stress protection, as it could be reproduced with both $\mathrm{NaOCl}$ and ozonated water. As the production of EW yields both FAC and non-chlorine reactive oxygen species (Jeong et al., 2009; Zhang et al., 2018), the results suggest that Met may protect against both types of active species. One possible explanation is that free or proteinincorporated Met acts as a ROS scavenger during EW treatment. Methionine residues in proteins are considered to confer a ROS scavenging action that may protect other residues from oxidative damage (Schindeldecker and Moosmann, 2015). In addition, reversible oxidation of Met residues regulates the activity of different proteins (Drazic et al., 2013; Nicklow and Sevier, 2020), while Met mis-incorporation into proteins may offer shortterm protection against oxidative stress (Netzer et al., 2009; Lee et al., 2014). The proposed role of Met in ROS scavenging is supported by the Met/MetO recycling system, where methionine sulfoxide reductases (MSRs) re-reduce oxidized methionine (Brot et al., 1981; Grimaud et al., 2001). Here, MSR overexpressing yeast cells had increased resistance to EW. We also observed several parallels between $\mathrm{EW}$ and $\mathrm{NaOCl}$ and, elsewhere, $\mathrm{HOCl}$ produced by neutrophils as part of the immune response increased Met oxidation in E. coli while elevated MSR expression gave increased bacterial survival of HOCl (Rosen et al., 2009). Replacing Met residues with norleucine in E. coli proteins increased the bacterium's sensitivity to $\mathrm{NaOCl}$, supporting the hypothesis that Met residues might protect proteins from FAC stress (Luo and Levine, 2009). In yeast, deletion of MSRA or double deletion of MSRA/MSRB increased $\mathrm{NaOCl}$ sensitivity, and overexpression of MSRA or Met-rich proteins protected against $\mathrm{NaOCl}$ (Tarrago et al., 2012), similar to the protective effect of MSR overexpression reported here. Interestingly, other amino acids (Trp, Tyr) that were as or more reactive with EW compared to Met did not provide protection when supplied to yeast prior to EW treatments. The lack of a specific oxidation repair system for these amino acids (such as the MSR system for Met) may explain why accumulation of non-Met amino acids does not improve yeast resistance to EW.

Increased oxidant resistance has recently been described after pre-culture of yeast cells with high lysine, similar to the methionine pre-culture here (Olin-Sandoval et al., 2019). However, lysine pre-culture did not improve EW recovery in this study (data not shown). The previously reported lysine effect was explained by potential regulatory effects of excess Lys entering polyamine metabolism, and by increased production of the ROS scavenger glutathione. The protective effect of Met preculture against EW may also, at least partly, be more indirect than purely ROS scavenging. It has been shown previously that elevated MetO levels or decreased reduced-Met lead to increased oxidative targeting and turnover of FeS clusters (Sideri et al., 2009). Accordingly, increasing the level (via pre-culture) or maintenance (MSR overexpression) of reduced Met should help to keep FeS clusters intact in oxidizing cellular environments. Oxidative stress in general is well known to target surfaceexposed FeS clusters in proteins (Imlay et al., 2019). FeS proteins are highly reactive with FAC (Albrich et al., 1981) and $\mathrm{NaOCl}$ may, potentially via ROS generation in cells, damage the clusters in bacterial FeS proteins (Romsang et al., 2018). This study shows that EW impairs activity of the FeS cluster 
protein aconitase, a known target of pro-oxidant agents (Lalève et al., 2016). Rli1 overexpression protected against EW, similar to a reported protective effect against several pro-oxidants (Alhebshi et al., 2012). Rli1 is required for the nuclear export of ribosomal subunits, initiation and termination of translation and ribosome recycling (Kispal et al., 2005; Schuller and Green, 2017). Rli1 function is highly conserved and essential for cells, requiring the mitochondrial and cytosolic FeS assembly machinery to provide its two [4Fe-4S] clusters, pathways that are ROS hyper-sensitive (Gomez et al., 2014; Paul et al., 2015). This study suggests that Rli1 could be a key target of EW, advancing our understanding of EW mode of action. The reported contribution of reduced Met to FeS cluster maintenance (Sideri et al., 2009) offers a further explanation for the protection by Met against EW, in addition to the potential ROS-scavenging mechanism discussed above.

\section{CONCLUSION}

Using a top-down approach leading from complex matrices to cellular targets, we show the impact of protein levels and amino acids (especially methionine and cysteine) on fungicidal efficacy of EW, which most likely arises from inactivation of the FAC in EW by these molecules. We also show that methionine plays a key role in the mechanism of EW action in fungal cells, as a direct ROS scavenger and/or as a protector of other primary ROS targets. Increasing the level of reduced Met, either by enhancing MetO reduction or by feeding more Met, may protect FeS cluster proteins. We show that FeS cluster proteins, essential for cell viability, may be major targets of EW. This work provides important insight into the mode of action of chlorine based sanitizers, and potentially other pro-oxidant products. Such knowledge could inform rational combination of EW with other treatments (often referred to as "hurdle" technology in the food industry) targeting complementary functions or processes in organisms. Furthermore, the data may help to understand and predict antimicrobial efficacy against different spoilage or pathogenic microorganisms in diverse industry or domestic settings. The data are particularly relevant in regions of the world where EW use relies on water sources that contain high levels of constituents such as the compounds identified here that inactivate EW. The results establish the benefits of a

\section{REFERENCES}

Albrich, J. M., McCarthy, C. A., and Hurst, J. K. (1981). Biological reactivity of hypochlorous acid: implications for microbicidal mechanisms of leukocyte myeloperoxidase. Proc. Natl. Acad. Sci. U.S.A. 78, 210-214. doi: 10.1073/pnas. 78.1.210

Alhebshi, A., Sideri, T. C., Holland, S. L., and Avery, S. V. (2012). The essential iron-sulfur protein Rli1 is an important target accounting for inhibition of cell growth by reactive oxygen species. Mol. Biol. Cell 23, 3582-3590. doi: 10.1091/mbc.e12-05-0413

Avery, S. V. (2011). Molecular targets of oxidative stress. Biochem. J. 434, 201-210. doi: 10.1042/bj20101695

Baggio, A., Marino, M., Innocente, N., Celotto, M., and Maifreni, M. (2020). Antimicrobial effect of oxidative technologies in food processing: an overview. Eur. Food Res. Technol. 246, 669-692. doi: 10.1007/s00217-020-03447-6 comprehensive top-down approach for understanding sanitizer activity, leading from the industrial application right down to molecular targets.

\section{DATA AVAILABILITY STATEMENT}

All datasets presented in this study are included in the article/Supplementary Material.

\section{AUTHOR CONTRIBUTIONS}

FW: experimentation and data analysis and manuscript original draft. FR, IS, RG, and SA: conceptualization, funding acquisition and supervision. RG and SA: project administration. FR, FW, IS, RG, and SA: manuscript review and editing. All authors contributed to the article and approved the submitted version.

\section{FUNDING}

This work was supported by the Engineering and Physical Sciences Research Council (Grant Number EP/N50970X/1). This was through a studentship award to FW by the EPSRC funded Engineering Water Resilience Thematic Doctoral Training Programme. Support from Ozo Innovations Ltd., in kindly supplying electrolyzed water is gratefully acknowledged.

\section{ACKNOWLEDGMENTS}

We thank Hannah Cooper and Sacha Mooney (University of Nottingham) for providing soil samples and associated chemical data.

\section{SUPPLEMENTARY MATERIAL}

The Supplementary Material for this article can be found online at: https://www.frontiersin.org/articles/10.3389/fmicb. 2020.575157/full\#supplementary-material

Baraibar, M. A., Ladouce, R., and Friguet, B. (2013). Proteomic quantification and identification of carbonylated proteins upon oxidative stress and during cellular aging. J. Prot. 92, 63-70. doi: 10.1016/j.jprot.2013. 05.008

Benjamini, Y., Krieger, A. M., and Yekutieli, D. (2006). Adaptive linear stepup procedures that control the false discovery rate. Biometrika 93, 491-507. doi: 10.1093/biomet/93.3.491

Block, S. S. (2001). Disinfection, Sterilization and Preservation, 5th Edn. Philadelphia, PA: Lippincott Williams \& Wilkins.

Brot, N., Weissbach, L., Werth, J., and Weissbach, H. (1981). Enzymatic reduction of protein-bound methionine sulfoxide. Proc. Natl. Acad. Sci. U.S.A. 78, 21552158. doi: $10.1073 /$ pnas.78.4.2155

Cardenas-Rodriguez, M., Chatzi, A., and Tokatlidis, K. (2018). Iron-sulfur clusters: from metals through mitochondria biogenesis to disease. J. Biol. Inorg. Chem. 23, 509-520. doi: 10.1007/s00775-018-1548-6 
Carmona-Gutierrez, D., Alavian-Ghavanini, A., Habernig, L., Bauer, M., Hammer, A., Rossmann, C., et al. (2013). The cell death protease Kexlp is essential for hypochlorite-induced apoptosis in yeast. Cell Cycle 12, 1704-1712. doi: $10.4161 /$ cc. 24801

Cater, J. H., Wilson, M. R., and Wyatt, A. R. (2019). Alpha-2-macroglobulin, a hypochlorite-regulated chaperone and immune system modulator. Oxid. Med. Cell Longev. 2019:5410657.

Chen, S., Rillig, M. C., and Wang, W. (2009). Improving soil protein extraction for metaproteome analysis and glomalin-related soil protein detection. Proteomics 9, 4970-4973. doi: 10.1002/pmic.200900251

Delaye, L., Becerra, A., Orgel, L., and Lazcano, A. (2007). Molecular evolution of peptide methionine sulfoxide reductases (MsrA and MsrB): on the early development of a mechanism that protects against oxidative damage. J. Mol. Evol. 64, 15-32. doi: 10.1007/s00239-005-0281-2

Drazic, A., Miura, H., Peschek, J., Le, Y., Bach, N. C., Kriehuber, T., et al. (2013). Methionine oxidation activates a transcription factor in response to oxidative stress. Proc. Natl. Acad. Sci. U.S.A. 110, 9493-9498. doi: 10.1073/pnas. 1300578110

FAO (2019). The State of Food and Agriculture 2019. Moving Forward on Food Loss and Waste Reduction. Rome: FAO.

Fernández-Niño, M., Pulido, S., Stefanoska, D., Pérez, C., González-Ramos, D., van Maris, A. J. A., et al. (2018). Identification of novel genes involved in acetic acid tolerance of Saccharomyces cerevisiae using pooled-segregant RNA sequencing. FEMS Yeast Res. 18:foy100.

Flemmig, J., Zschaler, J., Remmler, J., and Arnhold, J. (2012). The fluoresceinderived dye aminophenyl fluorescein is a suitable tool to detect hypobromous acid (HOBr)-producing activity in eosinophils. J. Biol. Chem. 287, 27913-27923. doi: 10.1074/jbc.m112.364299

Gil, M. I., Gómez-López, V. M., Hung, Y.-C., and Allende, A. (2015). Potential of electrolyzed water as an alternative disinfectant agent in the fresh-cut industry. Food Bioproc. Tech. 8, 1336-1348. doi: 10.1007/s11947-014-1444-1

Gits, J. J., and Grenson, M. (1967). Multiplicity of the amino acid permeases in Saccharomyces cerevisiae. 3. Evidence for a specific methionine-transporting system. Biochim. Biophys. Acta 135, 507-516. doi: 10.1016/0005-2736(67) 90040-5

Gomez, M., Pérez-Gallardo, R. V., Sánchez, L. A., Díaz-Pérez, A. L., Cortés-Rojo, C., Meza Carmen, V., et al. (2014). Malfunctioning of the iron-sulfur cluster assembly machinery in Saccharomyces cerevisiae produces oxidative stress via an iron-dependent mechanism, causing dysfunction in respiratory complexes. PLoS One 9:e111585. doi: 10.1371/journal.pone.0111585

Graça, A., Santo, D., Pires-Cabral, P., and Quintas, C. (2020). The effect of UV$\mathrm{C}$ and electrolyzed water on yeasts on fresh-cut apple at $4{ }^{\circ} \mathrm{C}$. J. Food Eng. 282:110034. doi: 10.1016/j.jfoodeng.2020.110034

Grimaud, R., Ezraty, B., Mitchell, J. K., Lafitte, D., Briand, C., Derrick, P. J., et al. (2001). Repair of oxidized proteins. Identification of a new methionine sulfoxide reductase. J. Biol. Chem. 276, 48915-48920. doi: 10.1074/jbc. m105509200

Harvey, H. J., Wildman, R. D., Mooney, S. J., and Avery, S. V. (2020). Soil aggregates by design: manufactured aggregates with defined microbial composition for interrogating microbial activities in soil microhabitats. Soil Biol. Biochem. 148:107870.

Hawkins, C. L., Pattison, D. I., and Davies, M. J. (2003). Hypochlorite-induced oxidation of amino acids, peptides and proteins. Amino Acids 25, 259-274. doi: 10.1007/s00726-003-0016-x

Hricova, D., Stephan, R., and Zweifel, C. (2008). Electrolyzed water and its application in the food industry. J. Food Prot. 71, 1934-1947. doi: 10.4315/ 0362-028X-71.9.1934

Huang, Y.-R., Hung, Y.-C., Hsu, S.-Y., Huang, Y.-W., and Hwang, D.-F. (2008). Application of electrolyzed water in the food industry. Food Cont. 19, 329-345. doi: 10.1016/j.foodcont.2007.08.012

Imlay, J. A., Sethu, R., and Rohaun, S. K. (2019). Evolutionary adaptations that enable enzymes to tolerate oxidative stress. Free Radic. Biol. Med. 140, 4-13. doi: 10.1016/j.freeradbiomed.2019.01.048

Jackman, T., and Hughes, C. (2010). Formation of trihalomethanes in soil and groundwater by the release of sodium hypochlorite. Ground Water Monit Remediat. 30, 74-78. doi: 10.1111/j.1745-6592.2009.01266.x

Jeong, J., Kim, C., and Yoon, J. (2009). The effect of electrode material on the generation of oxidants and microbial inactivation in the electrochemical disinfection processes. Water Res. 43, 895-901. doi: 10.1016/j.watres.2008. 11.033

Jeong, J., Kim, J. Y., Cho, M., Choi, W., and Yoon, J. (2007). Inactivation of Escherichia coli in the electrochemical disinfection process using a Pt anode. Chemosphere 67, 652-659. doi: 10.1016/j.chemosphere.2006.11.035

Jo, H.-Y., Tango, C. N., and Oh, D.-H. (2018). Influence of different organic materials on chlorine concentration and sanitization of slightly acidic electrolyzed water. LWT Food Sci. Technol. 92, 187-194. doi: 10.1016/j.lwt. 2018.02.028

Kaczmarek, M., Avery, S. V., and Singleton, I. (2019). Microbes associated with fresh produce: sources, types and methods to reduce spoilage and contamination. Adv. Appl. Microbiol. 107, 29-82. doi: 10.1016/bs.aambs.2019. 02.001

Kim, G., Weiss, S. J., and Levine, R. L. (2014). Methionine oxidation and reduction in proteins. Biochim. Biophys. Acta 1840, 901-905. doi: 10.1016/j.bbagen.2013. 04.038

Kispal, G., Sipos, K., Lange, H., Fekete, Z., Bedekovics, T., Janaky, T., et al. (2005). Biogenesis of cytosolic ribosomes requires the essential iron-sulphur protein Rlilp and mitochondria. EMBO J. 24, 589-598. doi: 10.1038/sj.emboj.7600541

Lalève, A., Vallières, C., Golinelli-Cohen, M.-P., Bouton, C., Song, Z., Pawlik, G., et al. (2016). The antimalarial drug primaquine targets Fe-S cluster proteins and yeast respiratory growth. Redox Biol. 7, 21-29. doi: 10.1016/j.redox.2015.10.008 Lan, L., Zhang, R., Zhang, X., and Shi, H. (2019). Sublethal injury and recovery of Listeria monocytogenes and Escherichia coli O157:H7 after exposure to slightly acidic electrolyzed water. Food Cont. 106:106746. doi: 10.1016/j.foodcont.2019. 106746

Le, D. T., Lee, B. C., Marino, S. M., Zhang, Y., Fomenko, D. E., Kaya, A., et al. (2009). Functional analysis of free methionine-R-sulfoxide reductase from Saccharomyces cerevisiae. J. Biol. Chem. 284, 4354-4364.

Lee, J. Y., Kim, D. G., Kim, B. G., Yang, W. S., Hong, J., Kang, T., et al. (2014). Promiscuous methionyl-tRNA synthetase mediates adaptive mistranslation to protect cells against oxidative stress. J. Cell Sci. 127, 4234-4245. doi: 10.1242/ jcs. 152470

Lehmann, J., and Kleber, M. (2015). The contentious nature of soil organic matter. Nature 528, 60-68. doi: 10.1038/nature16069

Liu, Q., Chen, L., Laserna, A. K. C., He, Y., Feng, X., and Yang, H. (2020). Synergistic action of electrolyzed water and mild heat for enhanced microbial inactivation of Escherichia coli O157:H7 revealed by metabolomics analysis. Food Cont. 110:107026. doi: 10.1016/j.foodcont.2019.107026

Liu, Q., Wu, J., Lim, Z. Y., Aggarwal, A., Yang, H., and Wang, S. (2017). Evaluation of the metabolic response of Escherichia coli to electrolysed water by $1 \mathrm{H} \mathrm{NMR}$ spectroscopy. LWT Food Sci. Technol. 79, 428-436. doi: 10.1016/j.lwt.2017. 01.066

Lu, C., Brauer, M. J., and Botstein, D. (2009). Slow growth induces heat-shock resistance in normal and respiratory-deficient yeast. Mol. Biol. Cell 20, 891-903. doi: 10.1091/mbc.e08-08-0852

Luo, S., and Levine, R. L. (2009). Methionine in proteins defends against oxidative stress. FASEB J. 23, 464-472. doi: 10.1096/fj.08-118414

Margenot, A. J., Calderón, F. J., Bowles, T. M., Parikh, S. J., and Jackson, L. E. (2015). Soil organic matter functional group composition in relation to organic carbon, nitrogen, and phosphorus fractions in organically managed tomato fields. Soil Sci. Soc. Am. J. 79, 772-782. doi: 10.2136/sssaj2015.02.0070

Menant, A., Barbey, R., and Thomas, D. (2006). Substrate-mediated remodeling of methionine transport by multiple ubiquitin-dependent mechanisms in yeast cells. EMBO J. 25, 4436-4447. doi: 10.1038/sj.emboj.7601330

Mikutta, R., Kleber, M., Kaiser, K., and Jahn, R. (2005). Review: Organic matter removal from soils using hydrogen peroxide, sodium hypochlorite, and disodium peroxodisulfate. Soil Sci. Soc. Am. J. 69, 120-135.

Netzer, N., Goodenbour, J. M., David, A., Dittmar, K. A., Jones, R. B., Schneider, J. R., et al. (2009). Innate immune and chemically triggered oxidative stress modifies translational fidelity. Nature 462, 522-526. doi: 10.1038/nature08576

Nicklow, E. E., and Sevier, C. S. (2020). Activity of the yeast cytoplasmic Hsp70 nucleotide-exchange factor Fes1 is regulated by reversible methionine oxidation. J. Biol. Chem. 295, 552-569. doi: 10.1074/jbc.ra119. 010125

Ogunniyi, A. D., Dandie, C. E., Ferro, S., Hall, B., Drigo, B., Brunetti, G., et al. (2019). Comparative antibacterial activities of neutral electrolyzed oxidizing water and other chlorine-based sanitizers. Sci. Rep. 9:19955. 
Olin-Sandoval, V., Yu, J. S. L., Miller-Fleming, L., Alam, M. T., Kamrad, S., Correia-Melo, C., et al. (2019). Lysine harvesting is an antioxidant strategy and triggers underground polyamine metabolism. Nature 572, 249-253. doi: 10.1038/s41586-019-1442-6

Oomori, T., Oka, T., Inuta, T., and Arata, Y. (2000). The efficiency of disinfection of acidic electrolyzed water in the presence of organic materials. Anal. Sci. 16, 365-369. doi: 10.2116/analsci.16.365

Panasenko, O. M., Gorudko, I. V., and Sokolov, A. V. (2013). Hypochlorous acid as a precursor of free radicals in living systems. Biochemistry 78, 1466-1489. doi: 10.1134/s0006297913130075

Pattison, D. I., and Davies, M. J. (2001). Absolute rate constants for the reaction of hypochlorous acid with protein side chains and peptide bonds. Chem. Res. Toxicol. 14, 1453-1464. doi: 10.1021/tx0155451

Paul, V. D., Mühlenhoff, U., Stümpfig, M., Seebacher, J., Kugler, K. G., Renicke, C., et al. (2015). The deca-GX3 proteins Yael-Ltol function as adaptors recruiting the $\mathrm{ABC}$ protein Rli1 for iron-sulfur cluster insertion. eLife 4:e08231.

Qiu, T. A., Nguyen, T. H. T., Hudson-Smith, N. V., Clement, P. L., Forester, D.-C., Frew, H., et al. (2017). Growth-based bacterial viability assay for interferencefree and high-throughput toxicity screening of nanomaterials. Anal. Chem. 89, 2057-2064. doi: 10.1021/acs.analchem.6b04652

Rahman, S., Khan, I., and Oh, D. H. (2016). Electrolyzed water as a novel sanitizer in the food industry: current trends and future perspectives. Compr. Rev. Food Sci. Food Saf. 15, 471-490. doi: 10.1111/1541-4337. 12200

Redmile-Gordon, M. A., Armenise, E., White, R. P., Hirsch, P. R., and Goulding, K. W. T. (2013). A comparison of two colorimetric assays, based upon Lowry and Bradford techniques, to estimate total protein in soil extracts. Soil Biol. Biochem. 67, 166-173. doi: 10.1016/j.soilbio.2013.08.017

Rimmer, D. L. (2006). Free radicals, antioxidants, and soil organic matter recalcitrance. Eur J Soil Sci 57, 91-94. doi: 10.1111/j.1365-2389.2005.00735.x

Romsang, A., Duang-Nkern, J., Khemsom, K., Wongsaroj, L., Saninjuk, K., Fuangthong, M., et al. (2018). Pseudomonas aeruginosa ttcA encoding tRNA-thiolating protein requires an iron-sulfur cluster to participate in hydrogen peroxide-mediated stress protection and pathogenicity. Sci. Rep. 8:11882.

Rosen, H., Klebanoff, S. J., Wang, Y., Brot, N., Heinecke, J. W., and Fu, X. (2009). Methionine oxidation contributes to bacterial killing by the myeloperoxidase system of neutrophils. Proc. Natl. Acad. Sci. U.S.A. 106, 18686-18691. doi: 10.1073/pnas.0909464106

Schindeldecker, M., and Moosmann, B. (2015). Protein-borne methionine residues as structural antioxidants in mitochondria. Amino Acids 47, 1421-1432. doi: 10.1007/s00726-015-1955-8

Schuller, A. P., and Green, R. (2017). The ABC(E1)s of ribosome recycling and reinitiation. Mol. Cell. 66, 578-580. doi: 10.1016/j.molcel.2017.05.017

Schwabe, A., and Bruggeman, F. J. (2014). Single yeast cells vary in transcription activity not in delay time after a metabolic shift. Nat. Commun. 5:4798.

Setsukinai, K., Urano, Y., Kakinuma, K., Majima, H. J., and Nagano, T. (2003). Development of novel fluorescence probes that can reliably detect reactive oxygen species and distinguish specific species. J. Biol. Chem. 278, 3170-3175. doi: 10.1074/jbc.m209264200

Sharma, V. K., and Graham, N. J. D. (2010). Oxidation of amino acids, peptides and proteins by ozone: a review. Ozone Sci. Eng. 32, 81-90. doi: 10.1080/ 01919510903510507
Sideri, T. C., Willetts, S. A., and Avery, S. V. (2009). Methionine sulphoxide reductases protect iron-sulphur clusters from oxidative inactivation in yeast. Microbiology 155, 612-623. doi: 10.1099/mic.0.022665-0

Sleutel, S., Leinweber, P., Ara Begum, S., Kader, M. A., and De Neve, S. (2009). Shifts in soil organic matter composition following treatment with sodium hypochlorite and hydrofluoric acid. Geoderma 149, 257-266. doi: 10.1016/j. geoderma.2008.12.004

Storkey, C., Davies, M. J., and Pattison, D. I. (2014). Reevaluation of the rate constants for the reaction of hypochlorous acid $(\mathrm{HOCl})$ with cysteine, methionine, and peptide derivatives using a new competition kinetic approach. Free Radic. Biol. Med. 73, 60-66. doi: 10.1016/j.freeradbiomed.2014.04.024

Sumner, E. R., Shanmuganathan, A., Sideri, T. C., Willetts, S. A., Houghton, J. E., and Avery, S. V. (2005). Oxidative protein damage causes chromium toxicity in yeast. Microbiology 151, 1939-1948. doi: 10.1099/mic.0.27945-0

Taniwaki, M. H., Pitt, J. I., and Magan, N. (2018). Aspergillus species and mycotoxins: occurrence and importance in major food commodities. Curr. Opin. Food Sci. 23, 38-43. doi: 10.1016/j.cofs.2018.05.008

Tarrago, L., Kaya, A., Weerapana, E., Marino, S. M., and Gladyshev, V. N. (2012). Methionine sulfoxide reductases preferentially reduce unfolded oxidized proteins and protect cells from oxidative protein unfolding. J. Biol. Chem. 287, 24448-24459. doi: 10.1074/jbc.m112.374520

UNESCO (2019). The United Nations World Water Development Report 2019: Leaving no one Behind. Paris: UNESCO.

Vallières, C., Holland, S. L., and Avery, S. V. (2017). Mitochondrial ferredoxin determines vulnerability of cells to copper excess. Cell Chem. Biol. 24, 1228-1237. doi: 10.1016/j.chembiol.2017.08.005

Wang, H., Ge, D., Cheng, Z., Zhu, N., Yuan, H., and Lou, Z. (2020). Improved understanding of dissolved organic matter transformation in concentrated leachate induced by hydroxyl radicals and reactive chlorine species. J. Hazard. Mater. 387:121702. doi: 10.1016/j.jhazmat.2019.121702

Wang, Y., Ji, D., Chen, T., Li, B., Zhang, Z., Qin, G., et al. (2019). Production, signaling, and scavenging mechanisms of reactive oxygen species in fruitpathogen interactions. Int. J. Mol. Sci. 20, 2994. doi: 10.3390/ijms20122994

Winter, J., Ilbert, M., Graf, P. C. F., Ozcelik, D., and Jakob, U. (2008). Bleach activates a redox-regulated chaperone by oxidative protein unfolding. Cell 135, 691-701. doi: 10.1016/j.cell.2008.09.024

$\mathrm{Xu}, \mathrm{G}$., and Chance, M. R. (2005). Radiolytic modification and reactivity of amino acid residues serving as structural probes for protein footprinting. Anal. Chem. 77, 4549-4555. doi: 10.1021/ac050299+

Zhang, J., Yang, H., and Chan, J. Z. Y. (2018). Development of portable flowthrough electrochemical sanitizing unit to generate near neutral electrolyzed water. J. Food Sci. 83, 780-790. doi: 10.1111/1750-3841.14080

Conflict of Interest: The authors declare that the research was conducted in the absence of any commercial or financial relationships that could be construed as a potential conflict of interest.

Copyright (c) 2020 Wohlgemuth, Gomes, Singleton, Rawson and Avery. This is an open-access article distributed under the terms of the Creative Commons Attribution License (CC BY). The use, distribution or reproduction in other forums is permitted, provided the original author(s) and the copyright owner(s) are credited and that the original publication in this journal is cited, in accordance with accepted academic practice. No use, distribution or reproduction is permitted which does not comply with these terms. 